\title{
Klasyfikacja czasowników nowogreckich \\ w czasach teraźniejszym i przeszłym niedokonanym
}

\section{Taxonomy of the Modern Greek Verbs in the Present and Imperfective Past Tense}

\section{Kamil Traba}

\author{
INSTITUTE OF LINGUISTICS, ADAM MICKIEWICZ UNIVERSITY \\ AL. NIEPODLEGŁOŚCI 4, 61-874 POZNAŃ
}

prooffek@gmail.com

\begin{abstract}
Abstrakt
Podczas przeprowadzania analizy systemu koniugacyjnego języka nowogreckiego pod kątem morfologii można zauważyć liczne podobieństwa pomiędzy różnymi klasami koniugacyjnymi. Ponadto, system ten można scharakteryzować jako stosunkowo regularny i symetryczny (pod kątem morfologii), wydzielone koniugacje nie obejmują wszystkich czasowników tego języka, pozostawiając ich część jako niezależne klasy fleksyjne. Rodzi się jednak pytanie, czy przy tak dużej regularności konieczny jest podział czasowników na koniugacje, obejmujące większą część czasowników nowogreckich, i niezależne klasy koniugacyjne.

W niniejszym artykule dokonuje się rewizji wybranych klasyfikacji nowogreckiego systemu koniugacyjnego w trybie oznajmującym czasów teraźniejszego i przeszłego niedokonanego pod kątem morfologicznym. Szczególną uwagę autor przypisuje analogiom pomiędzy formami II koniugacji i tzw. czasownikami ściągniętymi, co w konsekwencji prowadzi do zaproponowania nowej klasyfikacji systemu koniugacyjnego współczesnego języka nowogreckiego. Badania koncentrują się na budowie morfologicznej tematu/tematów, końcówek osobowych a także na relacjach pomiędzy nimi. Takie podejście umożliwiło zbadać podobieństwa i różnice pomiędzy formami czasowników niezależnie od koniugacji bądź klasy fleksyjnej do której należą.
\end{abstract}




\begin{abstract}
When the Modern Greek verbal system is analysed many similarities may be seen. Despite that, the system is divided into conjugations and inflectional classes that do not cover all verbs. Given that the Modern Greek verbal inflection can be characterised as regular and symmetric from the morphological point of view, the question whether it is necessary to distinguish conjugations with nonconjugational' inflectional classes as e.g. contracted verbs arises.

The objective is to review classifications of the conjugational systems of the Modern Greek verbs in the Indicative Mood of the Present and Imperfective Past Tenses and, in accordance to the morphological analysis of verbal forms, to propose a new one. The analysis concentrates on the morphology of verbal forms and on analogies between the second conjugation and the contracted verbs. The analysis is based on the morphological features of verbs. In other words, it concentrates on the distinction of a verbal stem or stems, personal endings and correlation between them. Such an approach enables one to observe similarities and differences among verbs, regardless of the conjugational class they represent. Consequently, it is possible to group verbs in accordance to the features of the stem and personal endings that are added, leading to a proposal of new classification of the Modern Greek verbal system.
\end{abstract}

\title{
1 Introduction
}

The Modern Greek verbal system is a very complex one, for it includes the category of person, number, time, aspect, voice, mood and diathesis. On the other hand, though, it is very symmetric and regular from the morphological point of view. Verbs can be easily grouped into two conjugations and fully follow their conjugational class. Furthermore, the personal endings, regardless of the conjugational class, share many similarities. Due to these similarities, some linguists believe that it is possible to find one universal set of endings (see part 2.3). However, despite that, with the two conjugations that may be applied to most verbs, there are smaller groups of verbs that are usually considered as constituting their own inflectional class (Triantafyllidis 1996 [1941], Holton, Mackridge, Philippaki-Warburton 1998, Mackridge 2004 and others). Nevertheless, many linguists note that the second conjugation resembles, to great extent, the e.g. contracted verbs.

Given the above, the objective of the paper is to review different models of the conjugational system of the Modern Greek language and, after analysing the verbal morphology, to propose a new model. In order to do so, the verbs are analysed on two levels: i) features of a stem: a) whether the verb requires one, two or more stems to be distinguished in order to be 
inflected, b) whether it ends in a consonant or a vowel, and ii) features of endings. The research concentrates, predominantly, on the similarities between the personal endings of different inflectional classes and on the stem-ending relations. The main area constitutes the second conjugation [in the traditional meaning, e.g. Holton, Mackridge, Philippaki-Warburton (1997), Mackridge (2004), Klairis Mpampiniotis (2005), etc.] and nonconjugational inflectional classes. It is caused by the fact, that these flectional patterns show many similarities in endings and stem formation and, what is more important, it seems that they start to merge creating in the consciousness of the Greek speakers a new productive conjugational class.

The issue discussed in the paper is restricted to the Present (Praesens) and Imperfective (Imperfectum) Tense of the Indicative Mood and concentrates mainly on the (traditional) second conjugation and contracted verbs. Despite that, the presented model contains the first conjugation as well, in order to contrast it with a new second conjugation. Nevertheless, it is not discussed in detail in the paper. Furthermore, the question of relations between conjugational classes and morphology of other tenses and moods (e.g. aorist, perfect, imperative etc.) is not arisen.

\section{Description of Selected Verbal Classifications}

As already mentioned, the Modern Greek verbal system seems to be highly regular and symmetric (from the morphological point of view). However, despite that, many different classifications might be proposed, in accordance to the methodology applied. Consequently, this part of the paper is dedicated to the presentation and review of some classifications proposed by different linguists.

\subsection{Triantafyllidis (1996 [1941])}

Following the Modern Greek Grammar of Triantafyllidis, the second conjugation is divided into four classes (two for each voice): i) first class active voice: verbs with the endings $-\dot{\omega},-\dot{\alpha} \varsigma,-\dot{\alpha}$ like e.g. $\alpha \gamma \alpha \pi-\dot{\omega}, \alpha \gamma \alpha \pi-\dot{\alpha} \varsigma$, $\alpha \gamma \alpha \pi-\dot{\alpha}$ (to love) or $\chi \tau v \pi-\dot{\omega}, \chi \tau v \pi-\dot{\alpha} \varsigma, \chi \tau v \pi-\dot{\alpha}$ (to hit), ii) second class - active voice: verbs ended in $-\dot{\omega},-\varepsilon i s,-\varepsilon \dot{l}$ e.g. $\theta \varepsilon \omega \rho-\dot{\omega}, \theta \varepsilon \omega \rho-\varepsilon i s, \theta \varepsilon \omega \rho$ - $\varepsilon \dot{i}$ (to

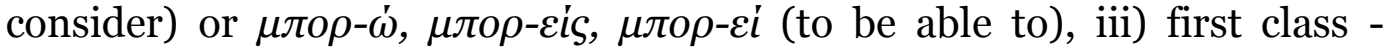

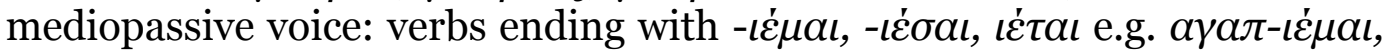
$\alpha \gamma \alpha \pi-\iota \dot{\varepsilon} \sigma \alpha \iota, \alpha \gamma \alpha \pi-\iota \dot{\varepsilon} \tau \alpha \iota$ (to be loved) or $\chi \tau v \pi-\iota \dot{\varepsilon} \mu \alpha \iota, \chi \tau v \pi-\iota \dot{\sigma} \sigma \alpha \iota, \chi \tau v \pi-\iota \dot{\tau} \tau \alpha \iota$ (to be hit), and iv) second class - mediopassive voice: verbs with the

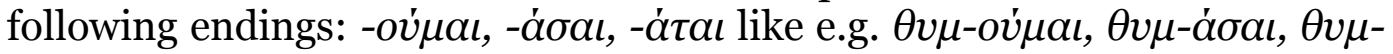

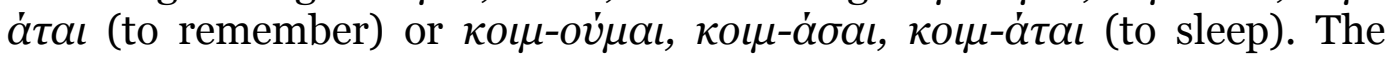
inflection of the verbs of the second conjugation is presented in the tables below. 
Table 2.1.1. First class of the second conjugation - active and mediopassive voices

\begin{tabular}{|c|c|c|c|c|}
\hline \multicolumn{5}{|c|}{ ACTIVUM } \\
\hline \multicolumn{3}{|c|}{ PRAESENS } & \multicolumn{2}{|c|}{ IMPERFECTUM } \\
\hline 1. Sg. & $-\dot{\omega}$ & 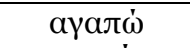 & -oúoa & аүалои́ба \\
\hline 2. Sg. & $-\dot{\alpha} \mathrm{s}$ & tảs & 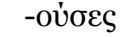 & ayo \\
\hline 3. Sg. & $-\dot{\alpha}$ & аүал $\dot{\alpha}^{3}$ & -oú & 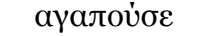 \\
\hline 1. Pl. & $-o u ́ \mu \varepsilon^{1}$ & аүалои่ $\mu \varepsilon$ & -oú $\sigma \alpha \mu \varepsilon$ & 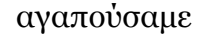 \\
\hline 2. Pl. & -áte & 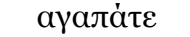 & 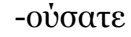 & 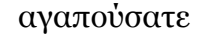 \\
\hline 3. Pl. & -oúv ${ }^{2}$ & аүaлoúv & -ov́oav & аүалои́баv \\
\hline \multicolumn{5}{|c|}{ MEDIOPASSIVUM } \\
\hline \multicolumn{3}{|c|}{ ESENS } & \multicolumn{2}{|c|}{ IMPERFECTUM } \\
\hline 1. Sg. & $-\imath \dot{\varepsilon} \mu \alpha \imath$ & 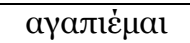 & -lópouv & 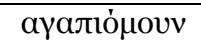 \\
\hline 2. Sg. & -lغ́øal & 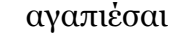 & -lóбouv & аүaлióбouv \\
\hline 3. Sg. & -létal & аүалlغ̇tal & -lótav & аүаліо́таv \\
\hline 1. Pl. & -ló $\mu \alpha \sigma \tau \varepsilon$ & аүаліо́ $\mu \alpha \sigma \tau \varepsilon$ & 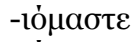 & $\alpha \gamma \alpha \pi$ tó $\mu \alpha \sigma \tau \varepsilon^{4}$ \\
\hline 2. Pl. & $-1 \varepsilon \dot{\sigma \tau \tau \varepsilon}$ & 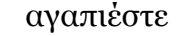 & 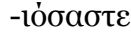 & 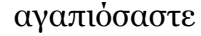 \\
\hline 3. Pl. & -loúvtal & аүалıоن́vtaı & -lóvtav & aүaлióvtav \\
\hline
\end{tabular}

Table 2.1.2. Second class of the second conjugation - active voice

\begin{tabular}{|c|c|c|c|c|c|c|c|c|}
\hline \multicolumn{9}{|c|}{ ACTIVUM } \\
\hline & \multicolumn{4}{|c|}{ PRAESENS } & \multicolumn{4}{|c|}{ IMPERFECTUM } \\
\hline & \multicolumn{2}{|r|}{ Sg. } & \multicolumn{2}{|r|}{ Pl. } & \multicolumn{2}{|r|}{ Sg. } & \multicolumn{2}{|r|}{ Pl. } \\
\hline 1. & $-\dot{\omega}$ & $\theta \varepsilon \omega \rho \dot{\omega}$ & $-o u ́ \mu \varepsilon$ & $\theta \varepsilon \omega \rho о \dot{\mu} \mu \varepsilon$ & -oúøa & $\theta \varepsilon \omega \rho o u ́ \sigma \alpha$ & -oú $\sigma \alpha \mu \varepsilon$ & $\theta \varepsilon \omega \rho o u ́ \sigma \alpha \mu \varepsilon$ \\
\hline 2. & sic & $\theta \varepsilon \omega \rho \varepsilon i \varsigma$ & $-\varepsilon \dot{i \tau \varepsilon}$ & $\theta \varepsilon \omega \rho \varepsilon i \tau \varepsilon$ & -oúoes & $\theta \varepsilon \omega \rho o u ́ \sigma \varepsilon \varsigma$ & 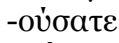 & $\theta \varepsilon \omega \rho o u ́ \sigma \alpha \tau \varepsilon$ \\
\hline 3. & $\begin{array}{l}\text { Elડ } \\
-\varepsilon \dot{~}\end{array}$ & $\theta \varepsilon \omega \rho \varepsilon i$ & -oúv & $\theta \varepsilon \omega \rho o u ́ v$ & 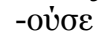 & $\theta \varepsilon \omega \rho о u ́ \sigma \varepsilon$ & 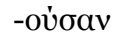 & $\theta \varepsilon \omega \rho o u ́ \sigma \alpha v$ \\
\hline
\end{tabular}

Table 2.1.3. Second class of the second conjugation - mediopassive voice

\begin{tabular}{|c|c|c|c|c|}
\hline \multicolumn{5}{|c|}{ MEDIOPASSIVUM } \\
\hline \multicolumn{3}{|c|}{ PRAESENS } & \multicolumn{2}{|c|}{ IMPERFECTUM } \\
\hline 1. Sg. & -oúuar & $\theta v \mu o u ́ \mu a l^{5}$ & -ónouv & $\theta v \mu o ́ \mu o v v$ \\
\hline 2. Sg. & -áơal & 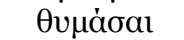 & -óoouv & $\theta$ Өóoouv \\
\hline 3. Sg. & -átaı & 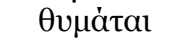 & -òtav & $\theta u \mu o ́ \tau a v$ \\
\hline 1. Pl. & 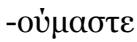 & $\theta v \mu о \cup \dot{\mu} \alpha \sigma \tau \varepsilon$ & 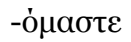 & $\theta v \mu o \dot{\mu a \sigma \tau \tau}$ \\
\hline 2. Pl. & 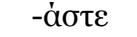 & $\theta u \mu \alpha \dot{\sigma} \tau \varepsilon$ & 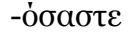 & $\theta v \mu o ́ \sigma \alpha \sigma \tau \varepsilon$ \\
\hline 3. Pl. & -oúvtal & $\theta u \mu o u ́ v \tau a l$ & -óvtav & $\theta u \mu o ́ v \tau a v$ \\
\hline
\end{tabular}

The verbs representing the second class and active voice are not inflected in accordance to the second class mediopassive voice. However,

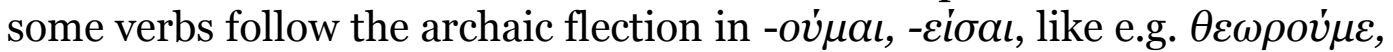
$\theta \varepsilon \omega \rho \varepsilon i \sigma \alpha \iota$ (to be considered) or $\sigma \tau \varepsilon \rho o v ́ \mu \alpha \iota, \sigma \tau \varepsilon \rho \varepsilon i \sigma \alpha \iota$ (to be deprived of), or

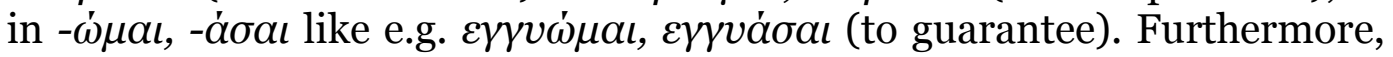
some verbs can represent both classes such as e.g. $\mu \iota \lambda \dot{\alpha} \omega, \mu \iota \lambda \dot{\alpha} \varsigma, \mu \iota \lambda \dot{\alpha}=\mu \iota \lambda \dot{\omega}$, $\mu \iota \lambda \varepsilon i \zeta, \mu \iota \lambda \varepsilon \dot{l}$, etc.

\footnotetext{
1 Also $\alpha \gamma \alpha \pi \dot{\alpha} \mu \varepsilon$.

2 Also $\alpha \gamma \alpha \pi \alpha ́ v(\varepsilon)$.

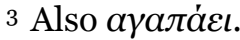

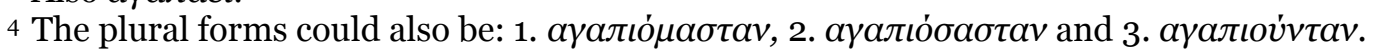

5 Also $\theta v \mu a ́ \mu \alpha ı$.
} 
Next to the I and II conjugation, there is a small group of verbs that follow their own flectional class. They are called contracted verbs ( $\sigma v v \eta \rho \eta \mu \varepsilon \dot{v} \alpha \rho \dot{\eta} \mu \alpha \tau \alpha$ ). These are the following verbs 6 : i) $\alpha \kappa o v ́ \omega$ (to hear),

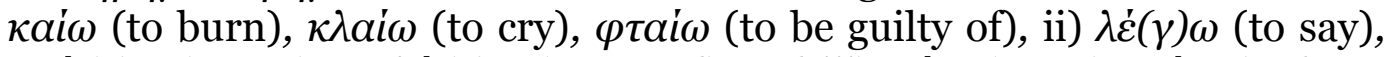
$\tau \rho \omega^{\prime}(\gamma) \omega$ (to eat), $\varphi v \lambda \dot{\alpha}(\gamma) \omega$ (to guard) and iii) $\pi \dot{\alpha} \omega$ (to go), $\varphi \dot{\alpha} \omega$ (to have eaten).

Table 2.1.4. Contracted verbs

\begin{tabular}{|c|c|c|c|c|}
\hline \multicolumn{5}{|c|}{ ACTIVUM } \\
\hline \multicolumn{3}{|c|}{ PRAESENS } & \multicolumn{2}{|c|}{ IMPERFECTUM } \\
\hline 1. Sg. & $-\omega$ & 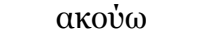 & $-\gamma \alpha$ & áкочүа \\
\hline 2. Sg. & $-s$ & akoús & $-\gamma \varepsilon \varsigma$ & áкоиүєs \\
\hline 3. Sg. & $-\varepsilon \mathrm{l}$ & 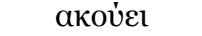 & $-\gamma \varepsilon$ & 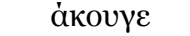 \\
\hline 1. Pl. & $-\mu \varepsilon$ & 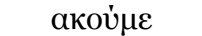 & $-\gamma \alpha \mu \varepsilon$ & 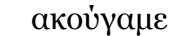 \\
\hline 2. Pl. & $-\tau \varepsilon$ & 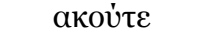 & $-\gamma \alpha \tau \varepsilon$ & 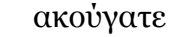 \\
\hline 3. Pl. & $-v(\varepsilon)$ & акоúv $(\varepsilon)$ & $-\gamma a v$ & áкочүav \\
\hline \multicolumn{5}{|c|}{ MEDIOPASSIVUM } \\
\hline \multicolumn{3}{|c|}{ PRAESENS } & \multicolumn{2}{|c|}{ IMPERFECTUM } \\
\hline 1. Sg. & $-\gamma o \mu \alpha$ & 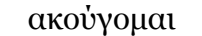 & & 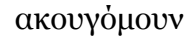 \\
\hline 2. Sg. & -үعoal & 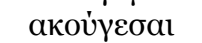 & $-\gamma$-үouv & 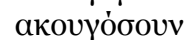 \\
\hline 3. Sg. & 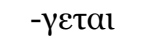 & акоúүعтац & $-\gamma 0000 \mathrm{~N}$ & 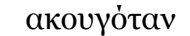 \\
\hline 1. Pl. & -үо́ $\mu \alpha \sigma \tau \varepsilon$ & акочүо̆ $\mu \alpha \sigma \tau \varepsilon$ & otav & 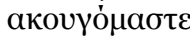 \\
\hline 2. Pl. & $-\gamma \varepsilon \sigma \tau \varepsilon$ & 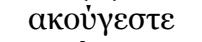 & 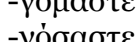 & 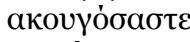 \\
\hline 3. Pl. & -үovtal & akoújovtal & - үóvtav & aкоúyovtav \\
\hline
\end{tabular}

The table above presents the flection of the exemplary verb $\alpha \kappa o v \omega$. The rest of the verbs are inflected analogically. However, it must be mentioned that the verbs: $\lambda \dot{\varepsilon}(\gamma) \omega, \tau \rho \dot{\omega}(\gamma) \omega$ and $\varphi v \lambda \dot{\alpha}(\gamma) \omega$ have two alternative forms of (and only of) the 1st person Singular: $\lambda \dot{\varepsilon} \omega: \lambda \dot{\varepsilon} \gamma \omega, \tau \rho \omega \omega \omega: \tau \rho \dot{\prime} \gamma \omega$ and $\varphi v \lambda \dot{\alpha} \omega$ : $\varphi v \lambda \dot{\alpha} \gamma \omega$. Furthermore, the verbs $\pi \dot{\alpha} \omega$ and $\varphi \dot{\alpha} \omega$ cannot be considered as a typical verbal forms, as they are, to a great extent, restricted to the perfective dependant forms of the active voice and are opposed to the imperfective forms based on $\pi \eta \gamma \alpha i v \omega$ and $\tau \rho \omega \omega$ (e.g. perfective future $\theta \alpha \pi \dot{\alpha} \omega: \theta \alpha$ $\pi \eta \gamma \alpha i v \omega)$. Nevertheless, the verb $\pi \alpha \omega$ is used in variation with $\pi \eta \gamma \alpha i v \omega$ in (but only in7) the Indicative Present.

Although the classification of the verbal system is presented clearly and in depth, it differs from both the contemporary Modern Greek norms and (especially) from the spoken language. To name some of the differences, a

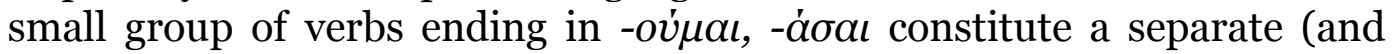
basic) flectional class, while a much more numerous (and more commonly used) group of verbs ending in -ov́ $\mu \alpha \iota,-\varepsilon i \sigma \alpha \iota$ is left outside these classes and is labelled as "archaic" (Trandafyllidis, 1996 [1941]: 171). It results in an inconsistency of the system, because regular verbs, like e.g. $\theta \varepsilon \omega \rho-\omega,-\varepsilon i ́ s$, form only the 'archaic' mediopassive voice. Furthermore, the classification

6 The verbs have been grouped in accordance to the Triantafyllidis' division to three conjugational classes of the contracted verbs (Triantafyllidis 1996: 172-3).

7 In accordance to the Grammar of Triantafyllidis. There are also (regional) imperfective imperative forms $\pi \dot{v} v \varepsilon, \pi \alpha \dot{\tau} \varepsilon$. However, their usage is geographically restricted to the southern Greece and, therefore, have not been mentioned in the work. 
proposed by Triantafyllidis does not show the relations between the active and mediopassive forms. For instance, it does not state nor directs the reader's attention in any way indicating that verbs of the active second class (table 2.1.2) form the mediopassive voice following the -ov́ inflectional class.

\subsection{Holton, Mackridge, Philippaki-Warburton (1998)}

In accordance to the Modern Greek Grammar written by Holton, Mackridge and Philippaki-Warburton, verbs of the second conjugation are divided into two classes a: class A (with the characteristic ' $\alpha$ ' vowel in active and ' $\iota$ ' in the mediopassive voice) and class B (with the characteristic ' $\varepsilon$ ' ' and ' $o v$ ' diphthongs in both voices). The flectional paradigms, presented in the tables below, are considered by the authors as the most commonly used in contemporary Greek.

Table 2.2.1. Second conjugation class $A$

\begin{tabular}{|c|c|c|c|c|}
\hline \multicolumn{5}{|c|}{ PRAESENS } \\
\hline \multicolumn{3}{|c|}{ ACTIVUM } & \multicolumn{2}{|c|}{ MEDIOPASSIVUM } \\
\hline 1. Sg. & $-\dot{\omega} / \dot{\alpha} \omega$ & 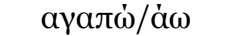 & $-l \dot{\varepsilon} \mu \alpha \imath$ & 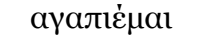 \\
\hline 2. Sg. & -às & ауала́s & -lécoal & аүалів́丿аı \\
\hline 3. Sg. & $-\dot{a}(\varepsilon \mathrm{l})$ & аүала̀ $(\varepsilon l)$ & -létal & 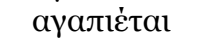 \\
\hline 1. Pl. & 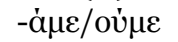 & аүала́ $\mu \varepsilon / o u ́ \mu \varepsilon$ & -ıó $\mu \alpha \sigma \tau \varepsilon$ & аүалtó $\mu \alpha \sigma \tau \varepsilon$ \\
\hline 2. $\mathrm{Pl}$. & -áte & аүала́te & $-l \dot{\varepsilon} \sigma \tau \varepsilon$ & aүaлtย่ $\sigma \tau \varepsilon^{8}$ \\
\hline 3. $\mathrm{Pl}$. & 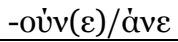 & 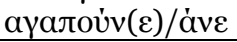 & -loúvtaı & аүалıоن่vtaı \\
\hline \multicolumn{5}{|c|}{ IMPERFECTUM } \\
\hline \multicolumn{3}{|c|}{ ACTIVUM } & \multicolumn{2}{|c|}{ MEDIOPASSIVUM } \\
\hline 1. Sg. & -oúoa & аүалои́ба & -lómouv & aүaлió $\mu$ ovv9 \\
\hline 2. Sg. & 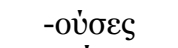 & 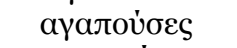 & -lóøouv & аүаліóбouv \\
\hline 3. $\mathrm{Sg}$. & $-o u ́ \sigma \varepsilon$ & 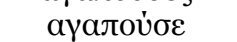 & -lótav & aүaлı̇́兀av \\
\hline 1. Pl. & -oú $\sigma \alpha \mu \varepsilon$ & 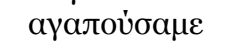 & -ıó $\mu \alpha \sigma \tau \varepsilon / \alpha v$ & $\alpha \gamma \alpha \tau i o ́ \mu \alpha \sigma \tau \varepsilon$ \\
\hline 2. $\mathrm{Pl}$. & 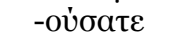 & аүалои́батв & 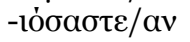 & 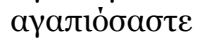 \\
\hline 3. Pl. & -oúбav & аүалои́баv & -lóvtav & 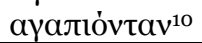 \\
\hline
\end{tabular}

It must be added that the inflection of the verbs representing the second conjugation class A can differ in accordance to the region, dialect, formality of an utterance and the speaker's individual preferences (example in the table 2.2.1). It is also mentioned that the active Imperfect may be formed by two different markers: $-o v \sigma$ - and $-\gamma$-. The difference is purely dialectical the former is preferred in Northern and the latter in Central and Southern Greece.

\footnotetext{
8 Also $\alpha \gamma \alpha \pi i o ́ \sigma \alpha \sigma \tau \varepsilon$.

9 The endings can also take an additional ' $\alpha$ ' or ' $\varepsilon$ ' vowels at the end giving the following forms in the singular: 1. $\alpha \gamma \alpha \pi \iota$ 'ó ' $\varepsilon$ ' in the first and second person plural: 1. $\alpha \gamma \alpha \pi \iota \dot{\mu} \mu \alpha \sigma \tau \alpha v, 2$. $\alpha \gamma \alpha \pi \iota \dot{\sigma} \alpha \sigma \tau \alpha v$ and 3. $\alpha \gamma \alpha \pi \iota v^{2} \tau \alpha \nu$.

${ }^{10}$ In the grammar (Grammatiki tis Ellinikis Glossas, 1998) there are three possible forms of the third person singular mentioned: $\alpha \gamma \alpha \pi \iota \dot{v} \tau \alpha v(\varepsilon), \alpha \gamma \alpha \pi \iota v \dot{v} \tau \alpha v(\varepsilon)$ and $\alpha \gamma \alpha \pi \iota \dot{v \tau o v \sigma \alpha v . ~}$
} 
Table 2.2.2. The mediopassive Present tense in - $\dot{\omega} \mu \alpha$ and active imperfect in $-\gamma \alpha$

\begin{tabular}{|c|c|c|c|c|}
\hline \multicolumn{5}{|c|}{ PRAESENS } \\
\hline \multicolumn{3}{|c|}{ PRESENS MEDIOPASSIVI } & \multicolumn{2}{|c|}{ IMPERFECTUM ACTIVI } \\
\hline 1. Sg. & $-\omega \dot{\mu} \mu a \imath$ & $\varepsilon \gamma \gamma v \omega \dot{\mu} \mu a \mathrm{r}$ & $-\gamma \alpha$ & аүáлаүa \\
\hline 2. Sg. & -áoal & eүүuáoal & $-\gamma \varepsilon \varsigma$ & аүа́лаүєs \\
\hline 3. Sg. & -átal & eүүuátal & $-\gamma \varepsilon$ & аүáлаүع \\
\hline 1. Pl. & -ı่́ $\mu \alpha \sigma \tau \varepsilon / \omega \dot{\omega} \mu \varepsilon \theta \alpha$ & 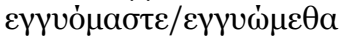 & $-\gamma \alpha \mu \varepsilon$ & 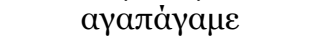 \\
\hline 2. Pl. & 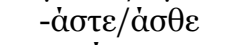 & 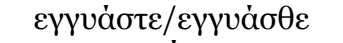 & $-\gamma a \tau \varepsilon$ & аүала́үате \\
\hline 3. Pl. & - & $\varepsilon \gamma \gamma \cup \omega \dot{v \tau a l ~}$ & $-\gamma a v(\varepsilon)$ & аүáлаүаv/аүала́үave \\
\hline
\end{tabular}

Table 2.2.3. Second conjugation class B

\begin{tabular}{|c|c|c|c|c|}
\hline \multicolumn{5}{|c|}{ ACTIVUM } \\
\hline \multicolumn{3}{|c|}{ PRAESENS } & \multicolumn{2}{|c|}{ IMPERFECTUM } \\
\hline 1. Sg. & $-\dot{\omega}$ & $\theta \varepsilon \omega \rho \omega \dot{~}$ & -oúoa & $\theta \varepsilon \omega \rho о \dot{\sigma \alpha}$ \\
\hline 2. Sg. & -eis & $\theta \varepsilon \omega \rho \varepsilon i \varsigma$ & 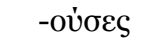 & 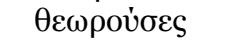 \\
\hline 3. Sg. & $-\varepsilon \dot{i}$ & $\theta \varepsilon \omega \rho \varepsilon \dot{~}$ & -oú $\sigma \varepsilon$ & $\theta \varepsilon \omega \rho o u ́ \sigma \varepsilon$ \\
\hline 1. Pl. & $-o \dot{\mu} \mu \varepsilon$ & $\theta \varepsilon \omega \rho о u \dot{\mu} \mu \varepsilon$ & -oú $\sigma \alpha \mu \varepsilon$ & $\theta \varepsilon \omega \rho о u ́ \sigma \alpha \mu \varepsilon$ \\
\hline 2. $\mathrm{Pl}$. & $-\varepsilon i \tau \varepsilon$ & $\theta \varepsilon \omega \rho \varepsilon i \tau \varepsilon$ & 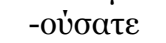 & $\theta \varepsilon \omega \rho о u ́ \sigma \alpha \tau \varepsilon$ \\
\hline 3. Pl. & -oúv & $\theta \varepsilon \omega \rho$ oúv $(\varepsilon)$ & 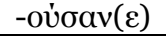 & $\theta \varepsilon \omega \rho o u ́ \sigma a v(\varepsilon)$ \\
\hline \multicolumn{5}{|c|}{ MEDIOPASSIVUM } \\
\hline \multicolumn{3}{|c|}{ PRAESENS } & \multicolumn{2}{|c|}{ IMPERFECTUM } \\
\hline 1. Sg. & -oúnal & $\theta \varepsilon \omega \rho o u ́ \mu a \imath$ & 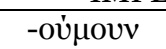 & $\theta \varepsilon \omega \rho o u ́ \mu o u v^{11}$ \\
\hline 2. Sg. & 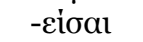 & $\theta \varepsilon \omega \rho \varepsilon i ́ \sigma a l$ & -oúoouv & $\theta \varepsilon \omega \rho o u ́ \sigma o u v$ \\
\hline 3. Sg. & -eital & $\imath \varepsilon \omega \rho \varepsilon i \tau a l$ & -oúvtav & $\theta \varepsilon \omega \rho o u ́ v \tau a v$ \\
\hline 1. Pl. & 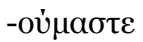 & $\theta \varepsilon \omega \rho \operatorname{u} \mu \alpha \sigma \tau \varepsilon$ & 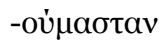 & $\theta \varepsilon \omega \rho o u ́ \mu \alpha \sigma \tau a v$ \\
\hline 2. $\mathrm{Pl}$. & $-\varepsilon \dot{\sigma} \sigma \tau \varepsilon$ & $\theta \varepsilon \omega \rho \varepsilon \dot{\sigma} \sigma \tau \varepsilon$ & 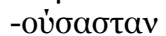 & $\theta \varepsilon \omega \rho$ \\
\hline 3. $\mathrm{Pl}$. & -oúvtal & $\theta \varepsilon \omega \rho o u ́ v \tau \alpha ı$ & -oúvtav & $\theta \varepsilon \omega \rho o u ́ v \tau \alpha \nu$ \\
\hline
\end{tabular}

What must be said is the fact that many verbs are not restricted to only one inflectional class e.g. $\alpha \kappa o \lambda o v \theta \dot{\omega}$ (to follow), $\kappa \rho \alpha \tau \dot{\omega}$ (to hold), $\pi \rho о \chi \omega \rho \omega ́$ (to proceed) (for more verbs see Holton, Mackridge, Philippaki-Warburton 1998: 131).

Outside the conjugational system of the Modern Greek language, a small group of contracted verbs may be found. These verbs are the same as mentioned by Triantafyllidis in the previous part of the paper. Furthermore, although, Holton, Mackridge and Philippaki-Warburton decided to mention only a single inflectional scheme (in opposition to Triantafyllidis' three schemes), they emphasise that other tense-aspect-mood-voice forms must be discussed separately for each of them (1998: 144-6) concerning other moods, times and voice. The inflection proposed in the work in question is identical to that presented in the Table 2.1.4.

The classification proposed by the three authors of the Modern Greek Grammar is a very well organised and systematically presented one. Its strong point is the fact that it takes into account the variety of the Modern Greek verbal system, by including a wide range of forms. However,

${ }^{11}$ The endings can also take an additional ' $\alpha$ ' or ' $\varepsilon$ ' vowels at the end giving the following

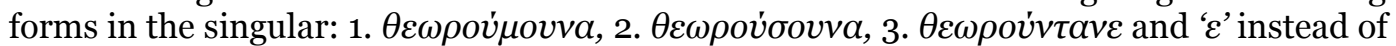
' $\alpha v$ ' in the first and second person plural: 1. $\theta \varepsilon \omega \rho o v \dot{\mu} \mu \sigma \tau \varepsilon$, 2. $\theta \varepsilon \omega \rho o v ́ \sigma \alpha \sigma \tau \varepsilon$. 
consequently, the classification leaves many verbs outside the 'regular' conjugational classes.

\subsection{Mackridge (2004)}

Mackridge in his work does not follow the traditional way of describing the verbal system dividing verbs into conjugations and inflectional classes, but distinguishes eight sets of endings that combine with two verbal categories (analogical to two conjugations ${ }^{12}$ ).13

Table 2.3.1. Sets of endings ${ }^{14}$

\begin{tabular}{|c|c|c|c|c|c|}
\hline & I & II & III & IV & V \\
\hline SG. & $\begin{array}{l}-0 \\
-i s \\
-i\end{array}$ & $\begin{array}{l}\text {-ó } \\
\text {-ís } \\
1\end{array}$ & $\begin{array}{l}\text {-áo } \\
\text {-ás } \\
\text {-ái }\end{array}$ & $\begin{array}{l}\text {-ó } \\
\text {-ás } \\
\text {-á }\end{array}$ & $\begin{array}{l}-a \\
\text {-es } \\
\text {-ee }\end{array}$ \\
\hline PL. & $\begin{array}{l}\text {-ume } \\
\text {-ete } \\
\text {-un(e) }\end{array}$ & $\begin{array}{l}\text {-úme } \\
\text {-íte } \\
\text {-ún(e) }\end{array}$ & $\begin{array}{l}\text {-áme } \\
\text {-áte } \\
\text {-án(e) }\end{array}$ & $\begin{array}{l}\text {-úme } \\
\text {-áte } \\
\text {-ún(e) }\end{array}$ & $\begin{array}{l}\text {-áme } \\
\text {-áte } \\
\text {--an/'- } \\
\text { an(e) }\end{array}$ \\
\hline & \multicolumn{2}{|c|}{ VI } & \multicolumn{2}{|l|}{ VII } & VIIa \\
\hline SG. & \multicolumn{2}{|c|}{-me } & '-mun(a) & & -mun(a) \\
\hline PL. & \multicolumn{2}{|c|}{$\begin{array}{l}\text {-maste } \\
\text {-ste/-saste } \\
\text {-nde }\end{array}$} & $\begin{array}{c}\text { '-maste/'-mastan } \\
\text { '-saste/'-sastan } \\
\text {-ndusan/-'-ndan(e)/ '-- } \\
\text { ndan }\end{array}$ & \multicolumn{2}{|c|}{$\begin{array}{l}\text { '-maste/'-mastan } \\
\text { '-saste/'-sastan } \\
\text { '-tan(e)/-'-san(e) }\end{array}$} \\
\hline
\end{tabular}

The above sets may be grouped in accordance to their features (all tenses and moods), like for instance:

- Voice: active voice is formed with the sets I, II, III, IV and V, while the mediopassive with the II, V, VI, VII and VIIb,

- Tense: non-past tenses are formed with the sets I, II, III, IV and VI and past tenses are formed with the I, V, VII and VIIb,

- Aspect: imperfective forms can use every set of endings, while the perfective forms are formed only with the sets I, II and IV,

- The sets III, IV are added directly to the root of the verb, VI, VII and VIIb are added after a conjunctive vowel, while I, II and V can be added either directly to the stem or after a specific time and voice marker,

- Formality: in the present tense active voice there is an opposition between the sets II and IV, which are formal and more characteristic

\footnotetext{
${ }^{12}$ The first class is represented by verbs, in which first person singular is stressed on the last syllable of the root while the second one has the ending stressed.

${ }^{13}$ Although the objective of the paper is to compare the paradigms of the verbs of the second conjugation with contracted verbs, the author decided to include all eight sets of endings, in order to maintain the its clarity.

14 The endings in the table are written in the Latin alphabet, in order to maintain the original form of the classification proposed by Mackridge.
} 
for the written language, and the set III, more often used in the everyday spoken language.

In accordance to the work, the set II is added to the theme of verbs from the subcategory IIa while the set III and IV to the verbs representing the subcategory IIb. Unfortunately, there are no morphological markers or features of the stem, which would indicate to which subcategory a specific verb belongs. Furthermore, in order to create an imperfective active past (imperfectum activi); the root of a verb must be exceeded by the thematic suffix -us- (for both verbal subcategories IIa and IIb) or -ag- (for the category IIb). The difference between them is of register: the former is more formal than the later. Much more space is dedicated to the sets VI-VIIb, due to the complexity of the vowel system that precedes these endings. The most characteristic sets are: $-i e^{-}:-i o-:-i u-,-u-:-i$ - and $-u-:-a-:-o-$. The first set is characteristic for the verbs from the subcategory IIb, the second for the verbs from the IIa and the third one for a small group of verbs like $\kappa o \iota \mu \alpha \dot{\alpha} \iota$ (to sleep) or $\theta v \mu \alpha \dot{\alpha} \mu \iota$ (to remember).

Due to the fact that Mackridge decided to describe verbal stems and the personal endings separately, he was not forced to describe verbs like

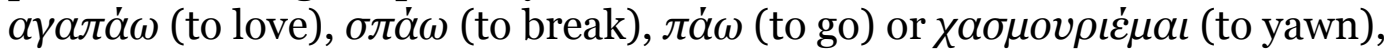
$\alpha \rho v o v ́ \mu \alpha \iota$ (to decline) and $\theta v \mu \alpha \dot{\mu} \mu \iota$ (to remember) as representing different inflectional classes. On the contrary, he was able to direct the reader's attention to the fact that all of these verbs use exactly the same endings (set IV and VI). The author of the Modern Greek grammar even took one step further and combined sets I-IV and VI-VIIb into two universal sets:

Table 2.3.2. Universal representation of the personal endings

\begin{tabular}{|c|c|c|c|}
\hline \multicolumn{2}{|c|}{ SETS I-IV } & \multicolumn{2}{c|}{ SETS VI-VIIb } \\
\hline SINGULAR & PLURAL & SINGULAR & PLURAL \\
\hline$-\Phi_{1}$ & $-\mathrm{me}$ & $-\mathrm{m}-$ & - mast- \\
$-\mathrm{s}$ & $-\mathrm{te}$ & $-\mathrm{s}-$ & $-(\mathrm{sa}) \mathrm{st}-$ \\
$-\Phi_{2}$ & $-\mathrm{n}(\mathrm{e})$ & $-\mathrm{t}-$ & $-\mathrm{nd}-$ \\
\hline
\end{tabular}

where $\Phi_{1}=o$ or $a$ and $\Phi_{2}=i, a$ or $e$.

Despite the fact that the approach adopted by Mackridge enabled him to better present many similarities in the verbal flection, it requires much information to be added in order to classify a verb to a specific flectional group, and therefore, to inflect it correctly. In other words, although Mackridge distinguishes eight groups of endings, he does not specify, which verbs are compatible with which group of endings. Consequently, in the author's opinion, the verbal system presented in such a way lacks the clarity of the traditional division into conjugations and inflectional classes. Furthermore, it might be difficult to understand for people who are not acquainted with the Modern Greek verbal system or for those who have merely started to learn the language. Nevertheless, the value of the work and of this approach may not be underestimated, as it seems to present the true 
'pure' personal endings (without conjunctive vowels or any other tensemood-voice markers).

\subsection{Klairis and Mpampiniotis (2005)}

Klairis and Mpampiniotis maintained in their work the traditional division of the Modern Greek verbs into two conjugations, analogically to the system presented in the part 2.3 (tables 2.2.1-3). However, despite that, they described verbal stems and endings separately, drawing the reader's attention to many similarities between different inflectional classes and subclasses. The system of verbal endings of the second conjugation is presented below in Table 2.4.1.

Table 2.4.1. Conjugational system of Modern Greek

\begin{tabular}{|c|c|c|c|c|c|c|c|}
\hline \multicolumn{8}{|c|}{ ACTIVUM } \\
\hline & & \multicolumn{4}{|c|}{$\mathrm{B}_{1}$} & \multicolumn{2}{|c|}{$\mathrm{B}_{2}$} \\
\hline 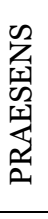 & $\begin{array}{l}1 \mathrm{Sg} . \\
2 \mathrm{Sg} . \\
3 \mathrm{Sg} . \\
1 \mathrm{Pl} . \\
2 \mathrm{Pl} . \\
3 \mathrm{Pl} .\end{array}$ & \multicolumn{2}{|c|}{ аүал- } & \multicolumn{2}{|c|}{$\begin{array}{c}-\dot{\alpha} \omega / \dot{\omega} \\
-\dot{\alpha} \varsigma \\
-\dot{\alpha}(\varepsilon \mathrm{l}) \\
-\dot{\alpha} \mu \varepsilon / o u \dot{\mu} \mu \varepsilon \\
-\dot{\alpha} \tau \varepsilon \\
-o u ́ v(\varepsilon) / \dot{\alpha} v(\varepsilon)\end{array}$} & $\theta \varepsilon \omega \rho-$ & $\begin{array}{l}-\dot{\omega} \\
-\varepsilon \dot{s} \\
-\varepsilon \dot{i} \\
-o u ́ \mu \varepsilon \\
-\varepsilon \dot{\tau} \varepsilon \\
\text {-oúv }\end{array}$ \\
\hline 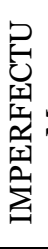 & $\begin{array}{l}1 \mathrm{Sg} . \\
2 \mathrm{Sg} . \\
3 \mathrm{Sg} . \\
1 \mathrm{Pl} . \\
2 \mathrm{Pl} . \\
3 \mathrm{Pl} .\end{array}$ & 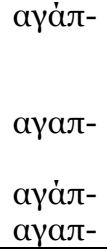 & 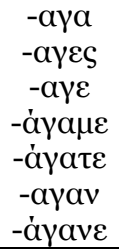 & $\begin{array}{c}- \\
- \\
- \\
-0\end{array}$ & 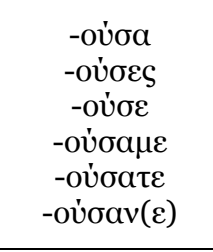 & $\theta \varepsilon \omega \rho-$ & 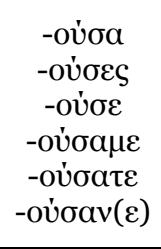 \\
\hline \multicolumn{8}{|c|}{ MEDIOPASSIVUM } \\
\hline & & \multicolumn{3}{|c|}{$\mathrm{B}_{1}$} & \multicolumn{3}{|c|}{$\overline{B_{2}}$} \\
\hline 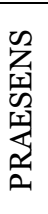 & $\begin{array}{l}1 \mathrm{Sg} . \\
2 \mathrm{Sg} . \\
3 \mathrm{Sg} . \\
1 \mathrm{Pl} . \\
2 \mathrm{Pl} . \\
3 \mathrm{Pl} .\end{array}$ & аүал- & \multicolumn{2}{|c|}{ 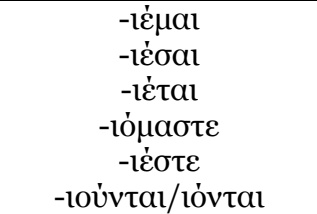 } & $\theta \varepsilon \omega \rho-$ & \multicolumn{2}{|c|}{ 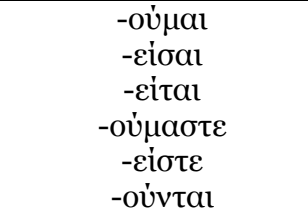 } \\
\hline 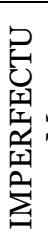 & $\begin{array}{l}1 \mathrm{Sg} . \\
2 \mathrm{Sg} . \\
3 \mathrm{Sg} . \\
1 \mathrm{Pl} . \\
2 \mathrm{Pl} . \\
3 \mathrm{Pl} .\end{array}$ & аүал- & 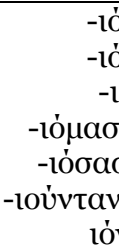 & 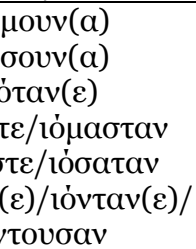 & $\theta \varepsilon \omega \rho-$ & $\begin{array}{r}-c \\
-c \\
-o u ́ \mu \alpha \\
-o u ́ \sigma \alpha \\
-\end{array}$ & 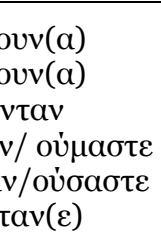 \\
\hline
\end{tabular}

As can be seen, some verbal classes as e.g. $\theta v \mu \alpha \dot{\alpha} \mu a \iota$ (to remember),

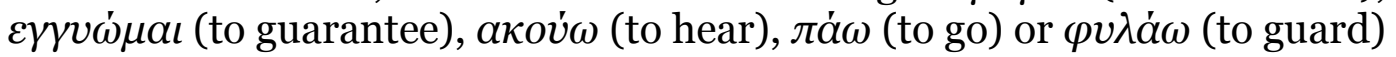
are not contained in the classification and are described separately. The most important group for the purposes of the paper is constituted by the contracted verbs that are represented by: $\alpha \kappa o v \dot{\omega} \omega, \kappa \alpha i \omega, \kappa \lambda \alpha i \omega, \lambda \dot{\varepsilon} \omega, \sigma \pi \alpha \dot{\alpha} \omega$, $\tau \rho \omega \dot{\omega}, \varphi \tau \alpha i \omega$ and to some extent by $\theta \dot{\varepsilon} \lambda \omega$, $\pi \dot{\alpha} \omega$ and $\varphi \dot{\alpha} \omega$. What is characteristic for Klairis' and Mpampiniotis' classification is the fact that they decided to add to the list verbs such as $\sigma \pi \alpha \dot{\alpha} \omega$ and especially $\theta \dot{\varepsilon} \lambda \omega$, which follow this scheme only partially (see the table below). 
Kamil Traba: Taxonomy of the Modern Greek Verbs in ...

Table 2.4.2. The contracted verbs and the $B_{1}$ conjugation of the active voice

\begin{tabular}{|c|c|c|c|c|c|c|c|}
\hline \multicolumn{8}{|c|}{ ACTIVUM } \\
\hline & & & $\overline{\text { ONTRA }}$ & VERBS & & $\bar{B}$ & \\
\hline \multirow{6}{*}{ 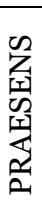 } & $1 \mathrm{Sg}$. & акой- & $-\omega$ & $\theta \dot{\varepsilon} \lambda-$ & $-\omega$ & аүала́- & $--\omega$ \\
\hline & $2 \mathrm{Sg}$. & & $-\varsigma$ & $\theta \varepsilon-$ & $-\mathrm{s}$ & & $-\varsigma$ \\
\hline & $3 \mathrm{Sg}$. & & $-\varepsilon l$ & $\theta \dot{\varepsilon} \lambda-$ & $-\varepsilon l$ & & $-\varepsilon l$ \\
\hline & $1 \mathrm{Pl}$. & & $-\mu \varepsilon$ & $\theta \dot{\varepsilon}-$ & $-\mu \varepsilon$ & & $-\mu \varepsilon$ \\
\hline & 2 Pl. & & $-\tau \varepsilon$ & & $-\tau \varepsilon$ & & $-\tau \varepsilon$ \\
\hline & $3 \mathrm{Pl}$. & & $-v \varepsilon$ & & $-v \varepsilon$ & & $-v \varepsilon$ \\
\hline \multirow{7}{*}{$\begin{array}{l}\frac{1}{a} \\
\text { 䆓 } \\
\text { 岁 }\end{array}$} & $1 \mathrm{Sg}$. & ákov- & $-\gamma \alpha$ & {$[\dot{\eta} \theta \varepsilon \lambda-$} & {$[-\alpha$} & аүа்ла- & $-\gamma \alpha$ \\
\hline & $2 \mathrm{Sg}$. & & $-\gamma \varepsilon$ & & $-\varepsilon \varsigma$ & & $-\gamma \varepsilon$ \\
\hline & $3 \mathrm{Sg}$. & & $-\gamma \varepsilon$ & & $-\varepsilon$ & & $-\gamma \varepsilon$ \\
\hline & $1 \mathrm{Pl}$. & & $-\gamma \alpha \mu \varepsilon$ & $\theta \dot{\varepsilon} \lambda-$ & $-\alpha \mu \varepsilon$ & & $-\gamma \alpha \mu \varepsilon$ \\
\hline & $2 \mathrm{Pl}$. & & $-\gamma \alpha \tau \varepsilon$ & & $-\alpha \tau \varepsilon$ & & $-\gamma \alpha \tau$ \\
\hline & $3 \mathrm{Pl}$. & & $-\gamma \alpha v$ & & $-\alpha v \varepsilon$ & & $-\gamma \alpha v$ \\
\hline & & aкoú- & $-\gamma \alpha v \varepsilon$ & $\dot{\eta} \theta \varepsilon \lambda-]$ & $-\alpha v]$ & аүала́- & $-\gamma \alpha v \varepsilon$ \\
\hline
\end{tabular}

Nevertheless, the verbal classes have been contrasted with each other, in order to show similarities between them. One of the similarities mentioned was an analogy between the contracted verbs and the $\mathrm{B}_{1}$ conjugation in the active voice. According to the authors, in the mind of Greek speakers a new opposition among the verbs started to shape: consonant-stem verbs (e.g. $\left.\delta \iota \alpha \beta \alpha \zeta_{-}, \kappa o \iota \tau \alpha \zeta-, \mu \alpha \theta \alpha \iota v-\right)$ and vowel-stem verbs $(\chi \tau v \pi \alpha-, \kappa o \iota \tau \alpha-, \alpha \gamma \alpha \pi \alpha-, \alpha \kappa o v-)$. That is the reason why in the spoken language the flection of the $B_{1}$ verbs resembles the flection of contracted verbs. Furthermore, the $\mathrm{B}_{2}$ class starts to be more and more restricted to the written and official language, while in the every-day usage it is being replaced by the $B_{1}$ class. Consequently, many verbs can follow both sets of

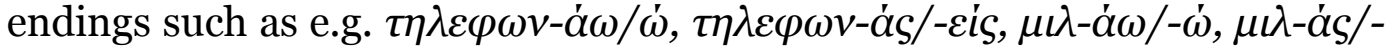

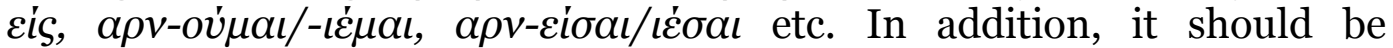
mentioned here that to the group of contracted verbs the verb $\sigma \pi \dot{\alpha} \omega^{15}$ - to break was added as well. It is because it follows this inflectional pattern fully.

The grammar written by Klairis and Mpampiniotis represents a solid source for knowledge about the Modern Greek morphological system. It provides inevitable data on the verbal flection and the verbal system in general. Its strong point is the fact that it includes more than one idea with a brief description and critical comment. Furthermore, it does not lack new ideas and observations on the subject discussed, e.g. comparison of the second conjugation $\mathrm{B}_{1}$ with the contracted verbs or consideration of a colloquial paradigm of the verb $\theta \dot{\varepsilon} \lambda \omega>\theta \dot{\varepsilon} s$ (to want). Nevertheless, although the authors noticed and mentioned the similarities between the second conjugation $\mathrm{B}_{1}$ and the contracted verbs, they decided to maintain the traditional verbal classification, leaving this group of verbs outside the system.

${ }_{15}$ A variation of $\sigma \pi \dot{\zeta} \zeta \omega$. 


\subsection{Ralli (2005)}

An entirely different classification of the Modern Greek verbal system was proposed by Ralli. She has not adopted the traditional system of two conjugations distinguished on the bases of the syllable stressed and concentrated on the phonological structure of the verbal stems. She noticed that the verbs of the second conjugation could be presented as follows: X(a) $\sim$ Xvowel ${ }^{16}$, where the former part represents the imperfective (also called present) stem and the later the perfective (aorist) stem. The inflection of such verbs is presented in the Table 2.5.1.

Table 2.5.1. The second conjugation.

\begin{tabular}{|c|c|c|c|c|}
\hline & & \multicolumn{2}{|c|}{ ACTIVUM } & MEDIOPASSIVUM \\
\hline 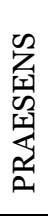 & $\begin{array}{l}1 \mathrm{Sg} . \\
2 \mathrm{Sg} . \\
3 \mathrm{Sg} . \\
1 \mathrm{Pl} . \\
2 \mathrm{Pl} . \\
3 \mathrm{Pl} .\end{array}$ & \multicolumn{2}{|c|}{ 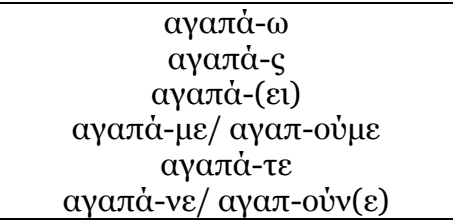 } & 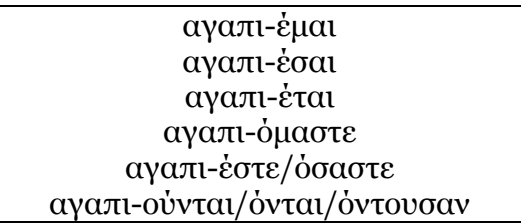 \\
\hline$\frac{\sqrt{2}}{a}$ & $\begin{array}{l}1 \mathrm{Sg} . \\
2 \mathrm{Sg} . \\
3 \mathrm{Sg} . \\
1 \mathrm{Pl} . \\
2 \mathrm{Pl} . \\
3 \mathrm{Pl} .\end{array}$ & 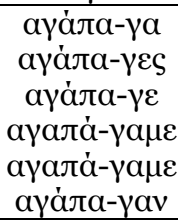 & 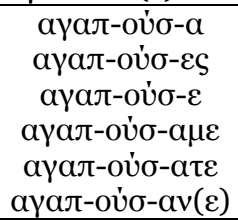 & 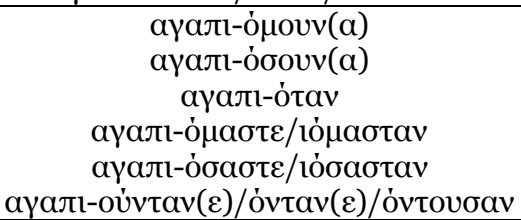 \\
\hline
\end{tabular}

Although this pattern applies to most verbs of the second conjugation, there is a smaller group of verbs, which has preserved the archaic conjugation called in the work $K T 2 \beta$ (II Conjugation class b) (see Table 2.5.2). This pattern, though, is characteristic for formal and written language but is disappearing from every-day usage. Consequently, such verbs follow both flectional schemes, having the $a$-stem based inflection as a variation. Furthermore, some verbal forms might have already disappeared completely e.g. the second person of both numbers of the

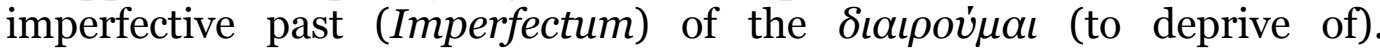
Nevertheless, there are also a few verbs (e.g. $\mu \pi о \rho \omega$ (to be able to)) that maintain this flectional pattern as the only variation.

Table 2.5.2. The second conjugation class $B$.

\begin{tabular}{|c|c|c|c|}
\hline & ACTIVUM & MEDIOPASSIVUM \\
\hline 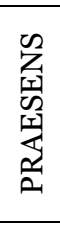 & $\begin{array}{l}1 \mathrm{Sg} . \\
2 \mathrm{Sg} . \\
3 \mathrm{Sg} . \\
1 \mathrm{Pl} . \\
2 \mathrm{Pl} . \\
3 \mathrm{Pl} .\end{array}$ & 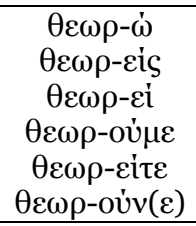 & 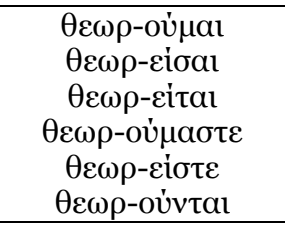 \\
\hline
\end{tabular}

${ }^{16} \mathrm{X}(\alpha) \sim \mathrm{X} \varphi \omega v \eta \dot{\varepsilon v}$ (Ralli 2005: 132). 


\begin{tabular}{|c|c|c|c|}
\hline 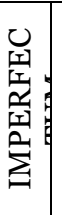 & $\begin{array}{l}1 \mathrm{Sg} . \\
2 \mathrm{Sg} . \\
3 \mathrm{Sg} . \\
1 \mathrm{Pl} . \\
2 \mathrm{Pl} . \\
3 \mathrm{Pl} .\end{array}$ & $\begin{array}{c}\theta \varepsilon \omega \rho-o u ́ \sigma-\alpha \\
\theta \varepsilon \omega \rho-o u ́ \sigma-\varepsilon \varsigma \\
\theta \varepsilon \omega \rho-o u ́ \sigma-\varepsilon \\
\theta \varepsilon \omega \rho-o u ́ \sigma-\alpha \mu \varepsilon \\
\theta \varepsilon \omega \rho-o u ́ \sigma-\alpha \tau \varepsilon \\
\theta \varepsilon \omega \rho-o u ́ \sigma-\alpha \nu\end{array}$ & 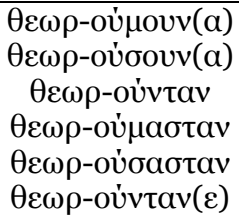 \\
\hline
\end{tabular}

The work of Ralli presents a new and fresh concept of the conjugational system of the Modern Greek verbs based on the phonological structure of a stem. Her research, in a way, resembles the mentioned work of Mackridge, although she does not go so far in her conclusions as he does. Nevertheless, their objectives are similar. What makes her work worth mentioning is the fact that she concentrates on the 'living' spoken language. Furthermore, on the basis of her analysis, she decided to distinguish II conjugation from the I in regard to the vowel changes of the stem. On the other hand, such an approach leads to a simplification of the system, as many inevitable questions are left without discussion. To exemplify this statement, the contracted verbs such as $\tau \rho \dot{\omega} \omega, \pi \dot{\alpha} \omega, \sigma \kappa \alpha \dot{\omega} \omega, \lambda \dot{\varepsilon} \omega$, as well as conjugational classes of $\theta v \mu \alpha \dot{\alpha} \mu \alpha \iota, \varepsilon \gamma \gamma v \dot{\omega} \mu \alpha \iota$, etc. are not discussed in any way, although they do not follow the X $(a) \sim$ Xvowel pattern.

\section{Proposal of a New Classification of the Modern Greek Verbal System}

As has been presented in the previous part of the paper, the Modern Greek verbal system may be considered as symmetric and regular from the morphological point of view. On the other hand, though, the question of the stem-ending relations is both complex and unclear. Simultaneously, a correct distinction between the ending and the stem constitutes a condition to group verbs into flectional classes and, consequently, to inflect them. This question has been raised by Klairis and Mpampiniotis (2005: 515-6), who discussed two possible ways of analysing the Modern Greek verbal structure: i) with universal past personal endings and ii) with three basic stems: imperfective (or present) stem, active and mediopassive perfective (aorist) stems. The disadvantage of the former is a necessity to distinguish many stems of the same verb, while the latter requires different sets of endings in regards to tense, voice and mood. Furthermore, depending on the approach adopted by an author, personal endings may differ to some extent. It is particularly evident when e.g. table 2.5.1 and 2.4.1 are compared.

Moreover, it has been mentioned that the verbal system is being reorganised shaping a new opposition between the consonant- and vowelstem conjugations. This idea is not only supported by the fact that in the spoken language the 'not-contracted' forms (e.g. $\alpha \gamma \alpha \pi \dot{\alpha} \omega, \mu \nu \lambda \dot{\alpha} \omega, \varphi \iota \lambda \dot{\alpha} \omega)$ are more often used than 'contracted' ones (e.g. $\alpha \gamma \alpha \pi \omega$ ', $\left.\mu \iota \lambda \omega^{\prime}, \varphi \iota \lambda \omega^{\prime}\right)$ (Holton, Mackridge, Philippaki-Warburton (1998), Mackridge (2004), Klairis, Mpampiniotis (2005) and others), but also by the tendency to replace the forms of the second conjugation class B (like e.g. $\left.o \delta \eta \gamma \omega^{\prime}, \kappa \iota v \omega^{\prime}, \tau \eta \lambda \varepsilon \varphi \omega v \omega^{\prime}\right)$

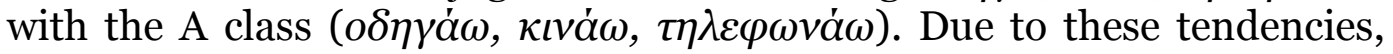
Ralli decided to distinguish the $a$-vowel pattern as the basic flectional 
scheme, considering the $e i$-vowel pattern to be archaic and not productive. Furthermore, there are small groups of verbs that do not follow the conjugational patterns, but possess their own inflectional classes. Simultaneously, many linguists indicate similarities between these groups and the 'regular' flection, especially between the, so-called, 'contracted' verbs and the A class of the second conjugation. Having that in mind the author decided to analyse the similarities mentioned and check whether these two conjugational classes could be merged.

\subsection{Verbal Stem}

The first step that must be undertaken when describing the verbal flection is the division of the stem, as it constitutes the very bases of every verbal form, and ending. As mentioned earlier in the paper, different scientists find that boundary either in a different way or even in a different position. Consequently, it can influence how different inflectional classes are found.

In the paper, in order classify a verb to the proper conjugational class, two forms are needed: the $1^{\text {st }}$ and the $2^{\text {nd }}$ person Singular of the indicative present.

\begin{tabular}{|c|c|c|c|c|c|}
\hline үра́ $\varphi \omega$ & $>$ & $\gamma \rho \alpha \varphi^{-}$ & үра́ $\varphi \varepsilon ı s$ & $>$ & $\gamma \rho \alpha \varphi-$ \\
\hline үра́ $\varphi о \mu \alpha \imath$ & $>$ & үраф- & үра́ & $>$ & үраф- \\
\hline$\delta ı \alpha \beta a ̉ \zeta \omega$ & $>$ & $\delta 1 \alpha \beta \alpha \zeta-$ & 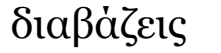 & $>$ & $\delta 1 \alpha \beta \alpha \zeta-$ \\
\hline 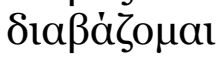 & $>$ & $\delta ı \dot{\alpha} \beta \alpha \zeta \zeta-$ & 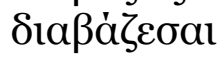 & $>$ & $\delta 1 \alpha \beta \alpha \zeta-$ \\
\hline$\theta \varepsilon \omega \rho \omega \dot{~}$ & $>$ & $\theta \varepsilon \omega \rho-$ & $\theta \varepsilon \omega \rho \varepsilon i \varsigma$ & $>$ & $\theta \varepsilon \omega \rho \varepsilon \iota^{-}$ \\
\hline$\theta \varepsilon \omega \rho o u ́ \mu a \imath$ & $>$ & $\theta \varepsilon \omega \rho o u-$ & $\theta \varepsilon \omega \rho \varepsilon i \sigma o \alpha$ & $>$ & $\theta \varepsilon \omega \rho \varepsilon \iota_{-}$ \\
\hline$\mu \pi о \rho \omega \dot{~}$ & $>$ & $\mu л о \rho-$ & нлорві & $>$ & $\mu \pi о \rho \varepsilon l-$ \\
\hline$\mu \nu \lambda \dot{\omega}$ & $>$ & $\mu \mathrm{\imath} \lambda-$ & $\mu \nu \lambda \dot{\alpha} s$ & $>$ & $\mu \nu \lambda \alpha-$ \\
\hline$\mu \iota \lambda \dot{a} \omega$ & $>$ & $\mu \mathrm{l} \lambda \alpha-$ & $\mu \nu \lambda \alpha_{S}$ & $>$ & $\mu \mathrm{u} \lambda \alpha-$ \\
\hline$\mu \mathrm{\lambda} \lambda \mathrm{l} \dot{\varepsilon} \mu \alpha \mathrm{l}$ & $>$ & $\mu \mathrm{l} \lambda \mathrm{l \varepsilon}-$ & $\mu \lambda \lambda l^{\prime} \varepsilon \sigma \alpha \iota$ & $>$ & $\mu \nu \lambda_{1 \varepsilon-}$ \\
\hline 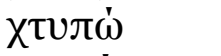 & $>$ & $\chi \tau U \pi-$ & 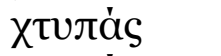 & $>$ & хтила- \\
\hline 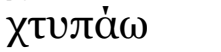 & $>$ & хтuла- & Xтuлás & $>$ & хтuла- \\
\hline 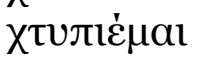 & $>$ & XтUлเع- & 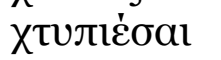 & $>$ & Xтuлtع- \\
\hline 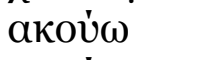 & $>$ & akov- & akoús & $>$ & akov- \\
\hline 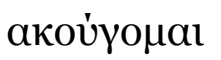 & $>$ & akouy- & 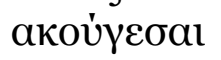 & $>$ & akovy- \\
\hline$\lambda \dot{\varepsilon} \omega$ & $>$ & $\lambda \varepsilon-$ & $\lambda \varepsilon \varsigma$ & $>$ & $\lambda \varepsilon-$ \\
\hline$\lambda \dot{\varepsilon} \gamma о \mu \alpha \imath$ & $>$ & $\lambda \varepsilon \gamma^{-}$ & $\lambda \dot{\varepsilon} \gamma \varepsilon \sigma \alpha \iota$ & $>$ & $\lambda \varepsilon \gamma-$ \\
\hline$\theta v \mu o u ́ \mu a 1^{17}$ & $>$ & $\theta v \mu o u ́-$ & $\theta v \mu a ́ \sigma \alpha ı$ & $>$ & $\theta v \mu \alpha-$ \\
\hline 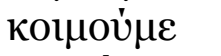 & $>$ & коцноv- & 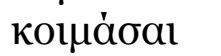 & $>$ & коц $\mu \alpha-$ \\
\hline$\varepsilon \gamma \gamma \cup \omega \dot{\mu} \mu \alpha \imath$ & $>$ & $\varepsilon \gamma \gamma \cup \omega-$ & عүүuáoal & $>$ & $\varepsilon \gamma \gamma v \alpha-$ \\
\hline$\varepsilon \xi \alpha \rho \tau \omega \dot{\mu} \mu \alpha \imath$ & $>$ & $\varepsilon \dot{\xi} \alpha \rho \tau \omega-$ & 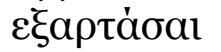 & $>$ & $\varepsilon \xi \alpha \rho \tau \alpha-$ \\
\hline
\end{tabular}

In accordance to these two forms, one can distinguish the following types of verbs:

- With one stem like e.g. $\gamma \rho \alpha \dot{\alpha} \varphi \omega>\gamma \rho \alpha \varphi-, \mu \iota \lambda \dot{\alpha} \omega, \mu \iota \lambda \alpha-, \alpha \kappa o v ́ \omega>$ $\alpha \kappa o v-, \alpha \kappa o v ́ \gamma o \mu \alpha \iota>\alpha \kappa o v \gamma-$,

17 also $\theta v \mu \alpha \dot{\alpha} \mu a l$, which is more common now. 
Kamil Traba: Taxonomy of the Modern Greek Verbs in ...

- With two variations of the stem like e.g. $\theta \varepsilon \omega \rho o v ́ \mu \alpha \iota ~>\theta \varepsilon \omega \rho o v-$ $/ \theta \varepsilon \omega \rho \varepsilon i^{-}$,

- With three variations of the stem like e.g. $\theta \varepsilon \omega \rho \omega \dot{\omega}>\theta \varepsilon \omega \rho-/ \theta \varepsilon \omega \rho \varepsilon \iota^{-}$

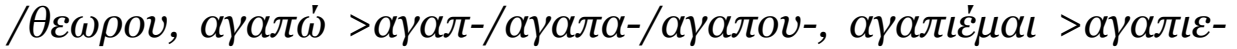

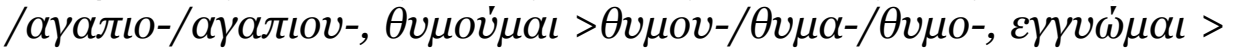
$\alpha \gamma \gamma v \omega-/ \varepsilon \gamma \gamma v \alpha-/ \varepsilon \gamma \gamma v o^{-}$

The above variations can be presented in a shorter form, by taking into account only the alternatives of the stem-vowel, e.g. $\alpha \gamma \alpha \pi \dot{\omega}(\varnothing, \alpha, o v)$,

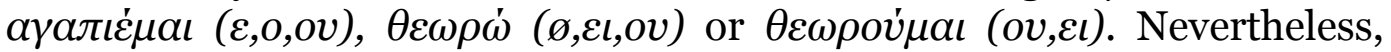
because the inflectional pattern of verbs is extremely regular, having the subject of the first and second person singular it is easy to predict other variations of the stem. Furthermore, the number of the stem variations can differ in regards to the region or individual preferences. For instance, the verbs $\alpha \gamma \alpha \pi i \varepsilon \mu \alpha$, that has been presented here as having three vowel variations of the stem, can also distinguish only two of them: $\alpha \gamma \alpha \pi \iota \mathcal{c}$ - and aүaлı-. It depends on the $3^{\text {rd }}$ person plural that can have two

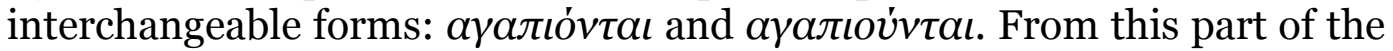
paper, the term 'stem' and 'stems' will refer also to the variations of the same stem. The author believes that the text will maintain clarity. Therefore, when it is stated that a verb has two or three stems, it should be understood that it forms two or three variations of a stem (in most cases based on a vowel alternation).

As may be seen from the above list, there are two groups of verbs: i) with one stem and ii) with more-than-one stem. The latter is represented by verbs traditionally considered as the II conjugation (both subclasses), that follow the more formal pattern, and by a small group of verbs like $\theta v \mu \alpha \dot{\mu} \alpha a / \theta v \mu o v ́ \mu \alpha \iota, \varepsilon \gamma \gamma v \omega ́ \mu \alpha$, etc, while the former contains verbs of the first conjugation, 'contracted' verbs and the more colloquial model of the second conjugation A.

It should be noted here that most 'contracted' verbs add to their mediopassive stem the consonant $-\gamma$ - However, it must not be mistaken with the $-\gamma$ - marker in the imperfective active past, which will be further discussed further on in the paper (see 3.3)

\subsection{Personal Endings}

As Mackridge (2004) noticed, it is possible to find a universal set of endings for all Modern Greek verbs. The only difference is the syllable stressed and the vowel that precedes it or, alternatively, whether the vowel is a part of the stem or of the ending. The classification of endings, presented below, is based on the later observation, though. The reason why the author decided to adopt this concept, is the fact, that although verbal forms like $\gamma \rho \dot{\alpha} \varphi \omega$, $\alpha \pi \circ \kappa \lambda \varepsilon i \omega, \mu \iota \lambda \dot{\alpha} \omega$ and $\alpha \kappa o v \omega$ are stressed at the second syllable (counting from the end), the last two represent a different conjugational classes than the other two. It must be also stated here that the author decided not to include the very formal and archaic endings e.g. $1^{\text {st }}$ person $\mathrm{pl}$. $-o \dot{ } \mu \theta \alpha, 2^{\text {nd }} \mathrm{pl}$. $-\varepsilon \sigma \theta \varepsilon$ or mediopassive $2^{\text {nd }} \mathrm{sg}$. $-\varepsilon \sigma o, 3^{\text {rd }} \mathrm{sg}$. $-\varepsilon \tau o$ etc. It is because such endings 
are restricted to a specific group of verbs, used in a specific genre of texts and situations (Holton, Mackridge, Philippaki-Warburton 1998, Klairis Mpampiniotis 2005 and others). However, even more important, such endings are highly unnatural for a common Greek speaker, who, although understanding more or less the meaning of such a form, cannot produce it unaided. Nevertheless, it could be easily changed, if needed, by addition of these few personal endings to the appropriate set(s) of endings.

Table 3.2.1. Personal endings

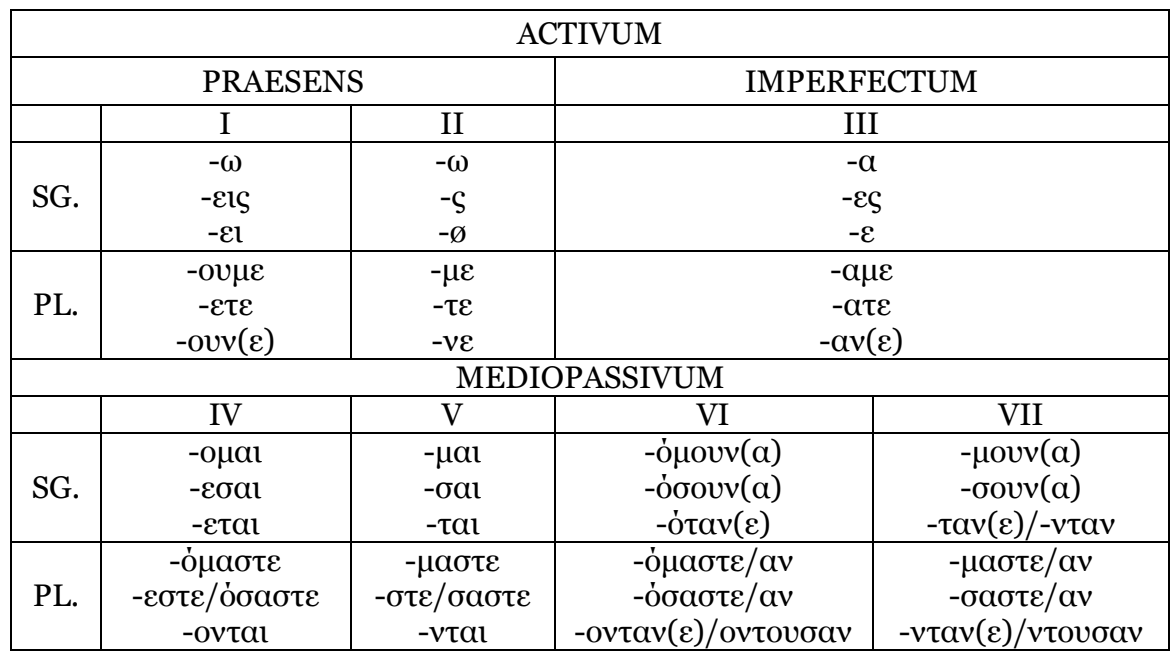

\subsection{Imperfective}

As it has been presented in the previous part of the paper (2.1-2.5), the imperfective of the second conjugation is formed with, either complex

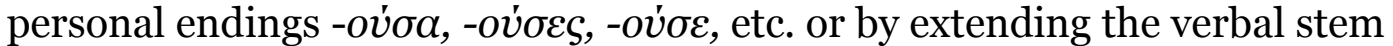
with suffix -ov́ $\sigma$-. In both cases the result is identical: $\theta \varepsilon \omega \rho o v \sigma \alpha \alpha, \alpha \gamma \alpha \pi o v ́ \sigma \alpha$, etc. There is, though, also a second, more colloquial and more commonly used in the central and southern Greece, form with $-\gamma$ - consonant that is added directly to the subject, resulting in the following forms: $\alpha \gamma \alpha \dot{\pi} \alpha \alpha \alpha$, $\mu i \lambda \alpha \gamma \alpha$, etc.

Table 3.3.1. Division of the active imperfective forms into stem and suffixes $^{18}$

\begin{tabular}{|c|c|c|}
\hline Stem & Sufix $_{1}$ & Personal ending \\
\hline$\theta \varepsilon \omega \rho \dot{v}^{-}$ & $-\sigma-$ & $-\alpha$ \\
$\mu \mathrm{\lambda}$ oú- & $-\sigma-$ & $-\alpha$ \\
$\mu \dot{\lambda} \lambda \alpha-$ & $-\gamma^{-}$ & $-\alpha$ \\
$\dot{\alpha} \kappa o v-$ & $-\gamma^{-}$ & $-\alpha$ \\
\hline
\end{tabular}

In the paper the -ov́ $\sigma$ - and the $-\gamma$-suffixes will not be considered as parts of the personal endings. Furthermore, in accordance to the previous part

${ }^{18}$ In the paper the Pseudo-Agglutinative approach of Joseph (Janda R.D., Joseph B. D. 1992a) has not been adopted, for the reasons mentioned in the paper. 
(see 3.2) the -ov' $\sigma$ - will be further divided into a vowel -ov-, that is a part of a stem (stem vowel), and the suffix $-\sigma$-. If the active imperfective and aorist forms of the verbs e.g. $\theta \varepsilon \omega \rho \omega$ or $\mu \iota \lambda \dot{\omega}$, were to be compared, it would be easily noticed that the only difference between these two aspects constitutes the stem vowel: imperfective -ov- and aoristic $-\eta-(\theta \varepsilon \omega \rho o v \sigma \alpha \alpha: \theta \varepsilon \omega \rho \eta \sigma \alpha$, $\mu \iota \lambda o v \sigma \alpha: \mu i \lambda \eta \sigma \alpha)$. These changes indicate that either $-\sigma$ - of the imperfective past and the $-\sigma$ - of the aorist represent two different (or complex) markers (therefore influencing the stem vowel differently), there is a hidden imperfective and aoristic marker between the vowel and the past marker $\sigma$ - or that the vowel does not constitute the part of the stem, but is a suffix as well (yet still not a part of a personal ending). Because the paper concentrates on the conjugational system, the first explanation is applied. It is caused by the fact that the conjugational system seems to be reshaping into consonant vs. vowel conjugation. By analysing the vowel as a suffix and not as a part of a stem, all verbs would represent the consonant verbs and the only exceptions would be inflected in accordance to the consonant flection. Furthermore, the stems $\theta \varepsilon \omega \rho o v$ - and $\alpha \gamma \alpha \pi \circ v^{-}$have already been distinguished in the previous part of the paper. The question, whether the $\sigma$ - markers of the imperfective past and aorist are homophonic, yet different, markers or whether still another 'invisible' marker is to be distinguished, is worth further study in the future.

It is, however, not true when considering the colloquial forms with $-\gamma$-. In such case, the suffix might be considered, not only as an extension of the present stem, but also as the imperfect marker - in opposition to the aoristic $-\sigma-$. As a result, a new morphological opposition between the aorist and imperfect form might be distinguished. Furthermore, given that the second conjugation with $\varepsilon$-stem is being replaced with the $\alpha$-stem conjugation, the aspectual opposition of the $-\gamma$ - and $-\sigma$ - markers can cover a wide range of Modern Greek verbs.

Given the above, two separate means of marking the imperfective past have been shaped: the marker $-\sigma$ - (with the respective stem) and the marker $-\gamma$-. They are inevitable to create an active imperfective past of the verbs of the II conjugation.

\subsection{Gamma of the 'contracted' verbs - part of the stem or an imperfective marker}

The 'contracted' verbs, as has been presented above, use the imperfective marker $-\gamma$ - in order to form the imperfective past. Moreover, this consonant

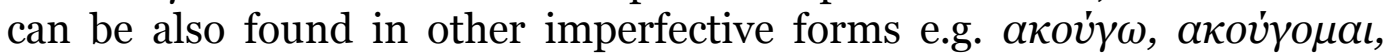

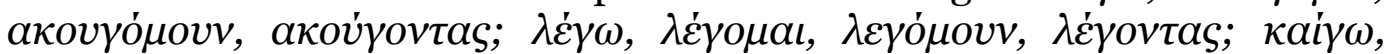

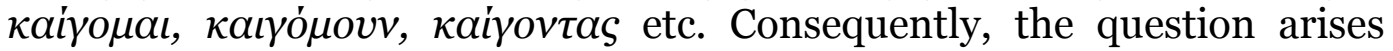
whether this consonant should be considered not only as an imperfective past marker, but also in a further sense of imperfective aspect. On the other hand, it cannot be used with other vowel-stemmed verbs e.g. $\alpha \gamma \alpha \pi \alpha \omega$, ${ }^{*} \alpha \gamma \alpha \pi \alpha \dot{\alpha} \gamma \omega,{ }^{*} \alpha \gamma \alpha \pi \dot{\alpha} \gamma o \mu \iota \alpha,{ }^{*} \alpha \gamma \alpha \pi \alpha \gamma o ́ \mu o v v,{ }^{*} \alpha \gamma \alpha \pi \dot{\gamma} \gamma o v \tau \alpha \varsigma$ etc., which use it only to form the imperfective past. This phenomenon might be explained by 
the fact that the verbs belong to a different conjugational class. ${ }^{19}$ Nevertheless, such an explanation is not consistent with the classification proposed in the present paper (see 3.5).

There is also another explanation to be proposed. It is based on the assumption that the imperfective $-\gamma$ - marker is not equal to the

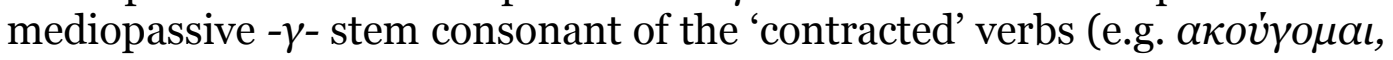

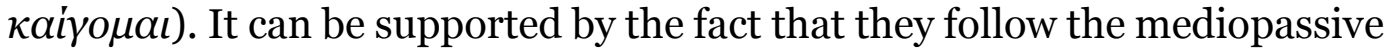
flection of the first (consonant) conjugation. Furthermore, the $-\gamma$ consonant may be observed also with other imperfective forms of the 'contracted' verbs like e.g. active imperfective participle or imperfective imperative. However, the question is, whether the $-\gamma$-present in such forms is in fact a suffix or a part of the stem. In the author's opinion, it is the latter. Nevertheless, it is extremely difficult to support that opinion, due to the homophony of the verbal forms. In other words, the imperfective past formed from the stem $\alpha \kappa o v \gamma$ - has (or would have) exactly the same form as the one formed from the stem $\alpha \kappa o v$ - with the imperfective marker $-\gamma$ - - in both cases the result is $\dot{\alpha} \kappa o v \gamma \alpha$.

As has already been mentioned in the paper, the so-called 'contracted' verbs are represented by a small group of verbs constituting their own inflectional class. Furthermore, Holton, Mackridge and PhilippakiWarburton (1998: 144) have added to this group the verb $\varphi v \lambda \dot{\alpha}(\gamma) \omega$, while Klairis and Mpampiniotis (2005: 5017) have also included the verb $\sigma \pi \dot{\alpha}(\zeta) \omega$. The later is most interesting, in relevance to the matter raised in this part of the paper, as it avoids the problem of homophony mentioned above. It is because the vowel and consonant stem variations are not based on the $-\gamma$ consonant and, therefore, it is easier to observe the stem changes among different forms of the verb in question.

Table 3.4.1. The imperfective forms of the verbs $\sigma \pi \alpha \dot{\alpha} \omega / \sigma \pi \dot{\alpha} \zeta \omega$ and $\lambda \dot{\varepsilon} \omega / \lambda \dot{\varepsilon} \gamma \omega$.

\begin{tabular}{|c|c|c|c|c|}
\hline & \multicolumn{2}{|c|}{$\sigma \pi \dot{\alpha} \omega, \lambda \dot{\varepsilon} \omega$} & \multicolumn{2}{|c|}{$\sigma \pi \dot{\alpha} \zeta \omega, \lambda \dot{\varepsilon} \gamma \omega$} \\
\hline & ACT. & $\begin{array}{l}\text { MED- } \\
\text { PASS }\end{array}$ & ACT. & $\begin{array}{l}\text { MED- } \\
\text { PASS. }\end{array}$ \\
\hline Praes & 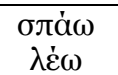 & - & $\begin{array}{l}\sigma \pi \dot{\sigma} \zeta \omega \\
\lambda \dot{\varepsilon} \gamma \omega\end{array}$ & 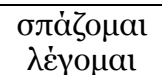 \\
\hline $\begin{array}{l}\text { Impe } \\
\text { rf. }\end{array}$ & $\begin{array}{c}\dot{\varepsilon} \delta \pi \alpha \gamma \alpha \\
\dot{\varepsilon} \lambda \varepsilon \gamma \alpha\end{array}$ & - & $\begin{array}{c}\dot{\varepsilon} \sigma \pi a \zeta \alpha \\
\dot{\varepsilon} \lambda \varepsilon \gamma \alpha\end{array}$ & 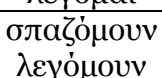 \\
\hline Impe & 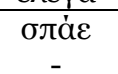 & - & $\begin{array}{l}\sigma \pi \dot{\zeta} \bar{\varepsilon} \\
\lambda \dot{\varepsilon} v \varepsilon\end{array}$ & - \\
\hline Part. & - & - & 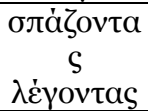 & $\lambda{ }^{-}{ }^{-}$ \\
\hline Con. & $\begin{array}{c}v \alpha \\
\sigma \pi \dot{\alpha} \omega \\
v \alpha \lambda \dot{\varepsilon} \omega\end{array}$ & - & $\begin{array}{c}v \alpha \text { бл } \dot{\alpha} \zeta \omega \\
v \alpha \lambda \dot{\varepsilon} \gamma \omega\end{array}$ & 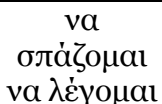 \\
\hline
\end{tabular}

${ }_{19}$ Due to the fact that the objective of the paper is to review the contemporary Modern Greek verbal system, the diachronic studies and approaches have been omitted (see e.g. Horrocks, 2010) 
In accordance with the table 3.4.1. the forms of the $\sigma \pi \dot{\alpha}(\zeta) \omega$ and $\lambda \dot{\varepsilon}(\gamma) \omega$ show a great resemblance. The only difference can be seen in the vowelstemmed imperative and in the consonant-stemmed participle. It must be also emphasised that neither of the verbs have a vowel-stemmed mediopassive voice. As a result, two complementary subjects must be distinguished: $\sigma \pi \alpha$ - that is used only in the active voice and $\sigma \pi \alpha \zeta$ - that form the mediopassive paradigm. The consonant stem $\sigma \pi \alpha \zeta$ - can also be used in the active voice as a variation.

What is important, is the fact that the imperfective past can be formed in two different ways, depending on the stem used: $\dot{\varepsilon} \sigma \pi \alpha \zeta \alpha$ from the stem $\sigma \pi \alpha \zeta$ - and $\dot{\varepsilon} \sigma \pi \alpha \gamma \alpha$ from the $\sigma \pi \alpha$-. Consequently, the imperfective $-\gamma$ - marker can be easily opposed to the stem consonant $-\zeta$ -

Analogically to the verb $\sigma \pi \alpha(\zeta) \omega$, the 'contracted' verbs can distinguish two stems: ended in a vowel or in a consonant, e.g. $\lambda \varepsilon-/ \lambda \varepsilon \gamma^{-}, \alpha \kappa o v-/ \alpha \kappa o v \gamma^{-}$, $\kappa \alpha l^{-} / \kappa \alpha \iota \gamma^{-}, \kappa \lambda \alpha \iota^{-} / \kappa \lambda \alpha \iota \gamma^{-}, \varphi \tau \alpha \iota^{-} / \varphi \tau \alpha \iota \gamma^{-}, \varphi v \lambda \alpha-/ \varphi v \lambda \alpha \gamma^{-}$etc. Both stems are complementary, for the first is used only in the active and the second mostly in the mediopassive voice. It is also used, in order to form the active participle. In addition, the active voice can be formed with the consonant stem as a variation. Nevertheless, such forms are mostly restricted to the formal, written language and dialectics (Holton, Mackridge, PhilippakiWarburton 1998, Mackridge 2004, Klairis, Mpampiniotis 2005 and others).

It is also worth mentioning that the imperfective past can be formed i) with the imperfective $-\gamma$ - marker added directly to the stem $\alpha \kappa o v$ - giving in a result $\alpha \kappa o v-\gamma-\alpha$ or ii) by adding the personal ending directly to the consonant stem $\alpha \kappa o v \gamma$ - leading to the form $\alpha \kappa o v \gamma-\alpha$. Nevertheless, although both forms are homophonic, the difference between them is analogical to the one mentioned above, i.e. $\dot{\varepsilon}-\sigma \pi \alpha-\gamma-\alpha$ : $\dot{\varepsilon}-\sigma \pi \alpha \zeta-\alpha$, where the $-\gamma$ - consonant of the first forms constitute an aspectual marker, while the $-\gamma-/-\zeta-$ consonants of the second forms are parts of the stem.

It must also be added that the flectional pattern followed by a verb is strictly related with the features of the stem itself. Therefore, the vowel-stem active forms follow the vowel conjugational class (II conjugation), while the consonant-stemmed mediopassive (and active) follows the consonant conjugational class (I conjugation).

\subsection{Conjugations and Conjugational Classes}

In the paper, the distinction of two conjugations has been maintained, although their distinction is based on the structure of the stem and its variations and not on the syllable stressed. Therefore, the I conjugation is represented mostly by the verbs, the stems of which end in a consonant and the II conjugation by verbs in which stems end in a vowel. However, there is a group of vowel-ended verbs that does not follow the II (vowel) conjugation. This group includes e.g. verbs in $-\varepsilon i \omega,-v \dot{\omega},-\dot{\varepsilon} \omega(\alpha \pi \circ \kappa \lambda \varepsilon i \omega$, $\delta\llcorner\varepsilon \eta \eta v v \dot{v} \omega, \delta \dot{\varepsilon} \omega)$. Moreover, the consonant conjugation is represented also by verbs in diphthongs $-\alpha v$ - and $-\varepsilon v$-. It is caused by their phonological realisation [av] and [ev]. Furthermore, an analogy between the stem type 
and the personal endings may be found. Consequently, they can be grouped into conjugations as well (see the table 3.2.1. and 3.5.1).

If the Ralli conception were to be adopted the I conjugation would constitute verbs, the stem of which could be represented as $\mathrm{X}\left(\mathrm{v}_{1}\right) \sim \mathrm{X}\left(\mathrm{v}_{1}\right)$. The first part is the stem used in the present tense and the second is a stem used in the perfective (aoristic) form. Analogically, the II conjugation would be (in most cases) presented as $\mathrm{X}\left(\mathrm{v}_{1}\right) \sim \mathrm{X}\left(\mathrm{v}_{2}\right)^{20}$. What is important, the difference between the conjugations would then be based on the change of a stem vowel. Nevertheless, the author believes that such measures are unnecessary, because the form of the second person singular provides all necessary data, in order to inflect a verb.

Table 3.5.1. Endings and conjugation

\begin{tabular}{|c|c|c|c|}
\hline \multicolumn{4}{|c|}{ ACTIVUM } \\
\hline \multicolumn{2}{|c|}{ PRAESENS } & \multicolumn{2}{|c|}{ IMPERFECTUM } \\
\hline $\mathrm{I}$ & II & \multicolumn{2}{|c|}{ I \& II } \\
\hline$-\omega$ & $-\omega$ & \multicolumn{2}{|l|}{$-\alpha$} \\
\hline$-\varepsilon I S$ & $-s$ & \multicolumn{2}{|l|}{$-\varepsilon \varsigma$} \\
\hline$-\varepsilon l$ & $-\varepsilon \mathrm{l}$ & \multicolumn{2}{|l|}{$-\varepsilon$} \\
\hline$-o v \mu \varepsilon$ & $-\mu \varepsilon$ & \multicolumn{2}{|l|}{$-\alpha \mu \varepsilon$} \\
\hline$-\varepsilon \tau \varepsilon$ & $-\tau \varepsilon$ & \multirow{2}{*}{\multicolumn{2}{|c|}{$\begin{array}{l}-\alpha \tau \varepsilon \\
-\alpha \gamma(\varepsilon)\end{array}$}} \\
\hline$-O u v(\varepsilon)$ & $-v \varepsilon$ & & \\
\hline \multicolumn{4}{|c|}{ MEDIOPASSIVUM } \\
\hline $\mathrm{I}$ & II & I & II \\
\hline$-o \mu \alpha r$ & $-\mu a \imath$ & -ómovv(a) & $-\mu \operatorname{ovv}(\alpha)$ \\
\hline$-\varepsilon \sigma \alpha l$ & $-\sigma a l$ & -óoouv $(\alpha)$ & $-\sigma o u ́ v(\alpha)$ \\
\hline$-\varepsilon \tau \alpha l$ & $-\tau a l$ & -ótav $(\varepsilon)$ & $-\tau a v(\varepsilon) /-v \tau \alpha v$ \\
\hline 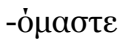 & $-\mu \alpha \sigma \tau \varepsilon$ & -ó $\mu \alpha \sigma \tau \alpha v /-o ́ \mu \alpha \sigma \tau \varepsilon$ & 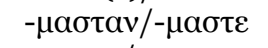 \\
\hline$-\varepsilon \sigma \tau \varepsilon$ & $-\sigma \tau \varepsilon$ & 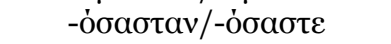 & $-\sigma \tau \alpha v /-\sigma \alpha \sigma \tau \varepsilon$ \\
\hline -ovtal & $-v \tau a l$ & 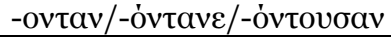 & 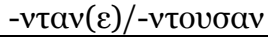 \\
\hline
\end{tabular}

According to the classification of verbs, they may be grouped into: i) one-stem verbs and ii) multiple-stem verbs, depending on their stem variations. These categories do not match the classification of personal endings presented in the table 3.5.1. It is caused by the fact that the first group (one-stem verbs) is represented by verbs of both consonant and vowel conjugational classes, while the second one contains only the second conjugation. When properties of the verbal stems and personal endings are combined, one receives a new verbal classification presented in the table $3 \cdot 5.2$.

Table 3.5.2. Inflection of verbs ${ }^{21}$

\begin{tabular}{|r|r|r|}
\hline & \multicolumn{3}{|c|}{ ACTIVUM } \\
\hline & ONE-STEM VERBS & MORE-THAN-ONE-STEM VERBS \\
\hline I & II & II \\
\hline
\end{tabular}

${ }^{20}$ Nevertheless, such representation does not cover all verbs, as some of them maintain the original sound like e.g. $\gamma \varepsilon \lambda \dot{\alpha} \omega: \gamma \varepsilon \dot{\lambda} \alpha \sigma \alpha, \delta \imath \psi \dot{\alpha} \omega$ : $\delta i \psi \alpha \sigma \alpha$, ect.

${ }^{21}$ In the table, only exemplary forms are presented. Others are formed by using other variations of the personal endings presented in the Tables 3.2.1 or 3.3.1. 
Kamil Traba: Taxonomy of the Modern Greek Verbs in ...

\begin{tabular}{|c|c|c|c|c|c|}
\hline$\kappa о \beta-$ & $\lambda \dot{\varepsilon}-$ & аүала́- & $\begin{array}{c}\theta \varepsilon \omega \rho-: \theta \varepsilon \omega \rho \varepsilon \dot{-}: \\
\theta \varepsilon \omega \rho o u ́\end{array}$ & $\begin{array}{c}\text { аүал- : аүала́- : } \\
\text { аүалоú- }\end{array}$ & \\
\hline 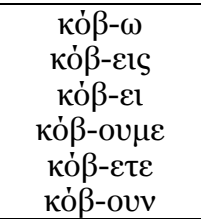 & $\begin{array}{l}\lambda \dot{\varepsilon}-\omega \\
\lambda \varepsilon-\varsigma \\
\lambda \dot{\varepsilon}-\varepsilon \imath \\
\lambda \dot{\varepsilon}-\mu \varepsilon \\
\lambda \dot{\varepsilon}-\tau \varepsilon \\
\lambda \dot{\varepsilon}-v \varepsilon\end{array}$ & 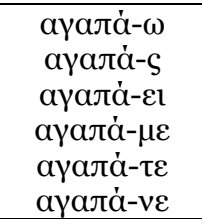 & $\begin{array}{c}\theta \varepsilon \omega \rho-\dot{\omega} \\
\theta \varepsilon \omega \rho \varepsilon \dot{-}-\varsigma \\
\theta \varepsilon \omega \rho-\varepsilon \dot{i} \\
\theta \varepsilon \omega \rho o \dot{-} \mu \varepsilon \\
\theta \varepsilon \omega \rho \varepsilon \dot{-}-\tau \varepsilon \\
\theta \varepsilon \omega \rho \dot{-}-v\end{array}$ & 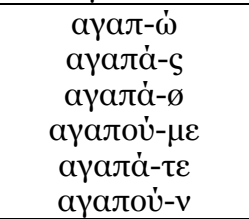 & \\
\hline$\kappa о \beta-$ & $\lambda \varepsilon-\gamma$ & $\alpha \gamma \alpha \pi \alpha-\gamma^{-}$ & $\theta \varepsilon \omega \rho$ oú- $\sigma-$ & аүалоن́- $\sigma-$ & \\
\hline 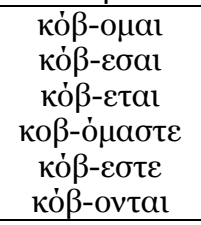 & $\begin{array}{l}\dot{\varepsilon} \lambda \varepsilon-\gamma-\alpha \\
\dot{\varepsilon} \lambda \varepsilon-\gamma-\varepsilon \varsigma \\
\dot{\varepsilon} \lambda \varepsilon-\gamma-\varepsilon \\
\lambda \dot{\varepsilon}-\gamma-\alpha \mu \varepsilon \\
\lambda \dot{\varepsilon}-\gamma-\alpha \tau \varepsilon \\
\dot{\varepsilon} \lambda \varepsilon-\gamma-\alpha \nu\end{array}$ & 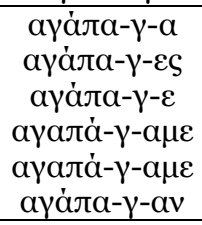 & $\begin{array}{c}\theta \varepsilon \omega \rho o \dot{-}-\sigma-\alpha \\
\theta \varepsilon \omega \rho o \dot{-}-\sigma-\varepsilon \varsigma \\
\theta \varepsilon \omega \rho o \dot{-}-\sigma-\varepsilon \\
\theta \varepsilon \omega \rho o \dot{-}-\alpha-\alpha \mu \varepsilon \\
\theta \varepsilon \omega \rho o \dot{-}-\sigma-\alpha \tau \varepsilon \\
\theta \varepsilon \omega \rho o \dot{-}-\sigma-\alpha v\end{array}$ & 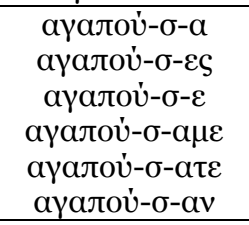 & \\
\hline \multicolumn{6}{|c|}{ MEDIOPASSIVUM } \\
\hline \multicolumn{2}{|c|}{$\mathrm{I}$} & & \multicolumn{3}{|c|}{ II } \\
\hline$\kappa о \beta-$ & $\lambda \varepsilon \gamma^{-}$ & & $\begin{array}{l}\theta \varepsilon \omega \rho o u ́-~: ~ \\
\theta \varepsilon \omega \rho \varepsilon \dot{-}-\end{array}$ & 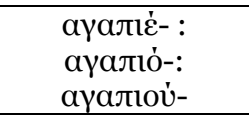 & 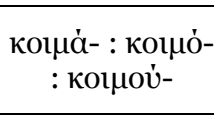 \\
\hline $\begin{array}{l}\dot{\varepsilon} \kappa o \beta-\alpha \\
\dot{\varepsilon} \kappa o \beta-\varepsilon \varsigma \\
\dot{\varepsilon} \kappa o \beta-\varepsilon \\
\kappa o ́ \beta-\alpha \mu \varepsilon \\
\kappa \dot{\beta} \beta-\alpha \tau \varepsilon \\
\dot{\varepsilon} \kappa o \beta-\alpha \nu\end{array}$ & $\begin{array}{c}\lambda \dot{\varepsilon} \gamma-0 \mu \alpha \mathrm{l} \\
\lambda \dot{\varepsilon} \gamma-\varepsilon \sigma \alpha \mathrm{l} \\
\lambda \dot{\varepsilon} \gamma-\varepsilon \tau \alpha \mathrm{l} \\
\lambda \varepsilon-\gamma \dot{o} \mu \alpha \sigma \tau \varepsilon \\
\lambda \dot{\varepsilon} \gamma-\varepsilon \sigma \tau \varepsilon \\
\lambda \dot{\varepsilon} \gamma-o v \tau \alpha \mathrm{l} \\
\end{array}$ & & $\begin{array}{c}\theta \varepsilon \omega \rho o \dot{-}-\mu \alpha \mathrm{l} \\
\theta \varepsilon \omega \rho \varepsilon \dot{-}-\sigma \alpha \mathrm{l} \\
\theta \varepsilon \omega \rho \varepsilon \dot{-}-\tau \alpha \mathrm{l} \\
\theta \varepsilon \omega \rho \circ \dot{-}-\mu \alpha \sigma \tau \varepsilon \\
\theta \varepsilon \omega \rho \varepsilon \dot{-}-\sigma \tau \varepsilon \\
\theta \varepsilon \omega \rho \operatorname{s}-v \tau \alpha \mathrm{l} \\
\end{array}$ & 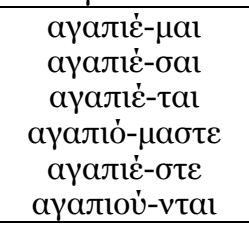 & 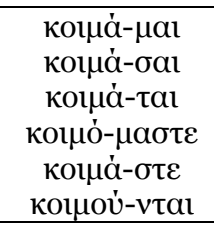 \\
\hline$\kappa о \beta-$ & $\lambda \varepsilon \gamma^{-}$ & & $\theta \varepsilon \omega \rho o u ́-$ & $\begin{array}{l}\text { aүaлió-: } \\
\text { aүaлtoú- }\end{array}$ & 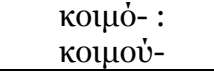 \\
\hline 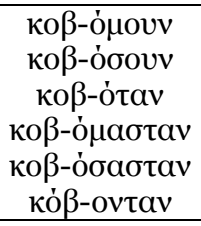 & 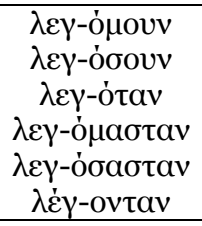 & & 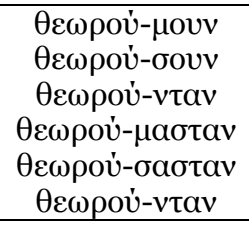 & 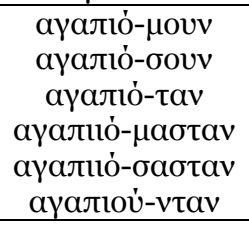 & 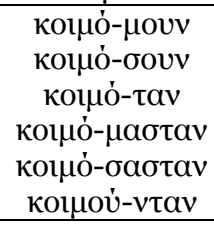 \\
\hline
\end{tabular}

The first thing that must be said about the one-stem verbs class is that it contains the I conjugation and the group of verbs often referred as 'contracted' (Triantafyllidis 1996 [1941], Holton, Mackridge, PhilippakiWarburton 1998, Klairis, Mpampiniotis 2005 and others). The characteristic feature of the 'contracted' verbs is the fact that they tend to follow the vowel conjugational model (II conjugation) in the active and the consonant conjugational model (II conjugation) in the mediopassive voice. In other words, they change the conjugational class from the II conjugation to the I conjugation. Nevertheless, it is also possible for them to follow the first conjugation fully in the active voice. This matter has been further discussed in 3.4 .

Moreover, the one-stem II conjugation could be considered as being 'under construction'. This is caused by the fact that verbs of the II conjugation with more than one stem start to be replaced in the spoken language by their one-stem equivalents. To put it differently, although there is a small group of verbs that are inevitably related with it (for instance $\alpha \kappa o v i \omega, \kappa \alpha i \omega, \kappa \lambda \alpha i \omega, \varphi \tau \alpha i \omega)$, most verbs constitute nothing more but a colloquial variation of the two/three-stem II conjugation. It must be also mentioned that such verbs do not follow the scheme of one-stem class in the mediopassive voice leaving the paradigm incomplete. 


\subsection{Discussion over the Proposed Classification}

The proposed classification is based on the similarities among the stem structures and personal endings of different conjugational classes and its objective is to distinguish such a classification that covers not only the verbs of the I and II conjugation, but also the 'left outside the pattern' ones. As a result, the approach enabled the author to group Modern Greek verbs into conjugations and classes in such a way, that, on the one hand, a distinction between different registers can be easily noted. On the other hand, a small group of 'contracted' verbs can also be included. Furthermore, it must be added that the proposed classification is compatible with the contemporary tendencies that reshape the Modern Greek language, for a group of 'contracted' verbs seems to be (although very slowly) growing. Such an impression is made by the fact that to this group a new verbs are being added in the colloquial language, e.g $\sigma \pi \dot{\alpha} \omega, \varphi v \lambda \dot{\alpha} \omega$, but also $\theta \dot{\varepsilon} \lambda \omega>\theta \varepsilon \varsigma, \theta \dot{\varepsilon} \mu \varepsilon, \theta \dot{\varepsilon} \tau \varepsilon$, $\theta \dot{\varepsilon} v \varepsilon$ or $\xi \dot{\varepsilon} \rho \omega>\xi \varepsilon \varsigma, \xi \dot{\varepsilon} \mu \varepsilon, \xi \dot{\varepsilon} \tau \varepsilon$. Nevertheless, the classification might be also applied to inflect more archaic forms e.g. $\pi \lambda \circ \rho \omega \dot{~(t o ~ p a y) . ~ H a v i n g ~}$ distinguished three stems: $\pi \lambda \circ \iota-, \pi \lambda \circ \iota \iota^{\prime}-$ and $\pi \lambda \circ \iota \nu^{\prime} v^{-}$and having added that the last one is characteristic for the plural, it would follow the standard pattern of the II conjugation. However, in order to do so, a set of archaic endings must be added first. The same can be stated concerning mediopassive verbs such as $\varepsilon \pi \iota \tau i \theta \varepsilon \mu a \iota$ (to attack). Having the archaic endings added and the stem $\varepsilon \pi \iota \tau \iota \theta \varepsilon$ - distinguished, it would be inflected analogically to the $\kappa o \iota \mu \alpha \dot{\alpha} \mu \iota$ class. In addition, because the classification is based on the endings added to a stem, it is highly oriented toward seeking and emphasising all kind of analogies among different verbs and conjugational classes. That is why the classification proposed, according to the author's opinion, would draw the student's attention to these analogies and would not only ease the learning process, but also decrease the amount of personal endings to master. Furthermore, as it has already been stated, the classification separates verbal forms used in the written language from those used in the spoken one. This way the distinction would be easier to understand than having them discussed as variations of a verb.

\section{Conclusion}

The presentation of different approaches to the question of the Modern Greek verbal inflection and a striking resemblance between the regular second conjugation and distinct inflectional patterns of the 'contracted' verbs lead to a new classification of the Modern Greek verbs. Although the traditional division, into two conjugations, has been maintained, the second conjugation has been greatly reorganised. As a result a new classification indicates not only differences on the morphological level (stem and endings), but also in use (register, region, variety). The proposed classification is a more universal one, in comparison with the others, as it does not only cover a greater number of verbs without distinguishing separate conjugational classes, but also because it is compatible with both contemporary tendencies of the language ( e.g. shaping of the new 
consonant: vowel flectional opposition or shifts between conjugational classes like $\sigma \pi \dot{\alpha} \zeta \omega>\sigma \pi \dot{\alpha} \omega$ or $\theta \dot{\varepsilon} \lambda \varepsilon \iota \varsigma>\theta \varepsilon \varsigma$ ) and (after minor adjustments) archaic flection. Such a classification might also been found useful in didactics, because it clearly points out similarities among different verbs and verbal classes and because it distinguishes more formal forms that are preferred in written texts from the ones commonly used in the spoken language. 


\section{References}

1. Chatzisavvidis, S., Chatzisavvidou, A. 2009. Grammatiki tis neas ellinikis glossas. A', B' kai G' Gymnasiou. Athenes: OEDB.

2. Fisiak, J. 1990. On the Present Status of Same Metatheoretical and Theoretical Issues in Contrastive Linguistics. w: Further insights into contrastive analysis. Amsterdam: Benjamins.

3. Holton, D., Mackridge, P., Philippaki-Warburton, E. 1998. Grammatiki tis Ellinikis Glossas. Athens: Ekdoseis Pataki.

4. Horrocks G. 2010. Greek. A History of the Language and its Speakers. Malden: Wiley-Blackwell.

5. Janda R.D., Joseph B. D. 1992a. Pseudo-Agglutinativeity in Modern Greek Verb-Inflection and "Elsewhere". w: Paper from the 28th Regional Meeting of the Chicago Linguistic Society, Vol. 1. Chicago: Chicago Linguistic Society.

6. Joseph B.D. 1992b. I morfosíndaksi tu neoelinikú rimatikú sinólu san morfolojía ke óxi síndaksi [The Morphosyntax of the Modern Greek Verbal Unit as Morphology and not Syntax]. w: Studies in Greek Linguistics (Proceedings of the 12th Annual Meeting of the Department of Linguistics, Aristotelian University of Thessaloniki). Thessaloniki: Aristotelian University of Thessaloniki.

7. Joseph B. D., Smirniotopoulos J.C. 1993. The Morphosyntax of the Modern Greek Verbal Complex as Morphology and not Syntax. w: Linguistics Inquiry24.2. Cambridge: MIT Press.

8. Katsouda, G. 2013. Ta Rimata se -amai tis Neoellinikis Koinis. w: Major Trends in Theoretical and Applied Linguistics. London: Versita.

9. Klairis, Ch., Mpampiniotis G. 2005. Grammatiki tis Neas Ellinikis. Athenes: ELLINIKA GRAMMATA.

10. Mackridge, P. 2004. I Neoelliniki Glossa: Perigrafiki Analisi tis Neoellinikis Koinis. Athenes: Ekdoseis Pataki - Glossologia 1.

11. Ralli, A. 2005. Morfologia. Athenes: Ekdoseis Pataki.

12. Triantafyllidis, M. 1996 [1941]. Neoelliniki Grammatiki tis Dimotikis. Thessaloniki: Institouto neoellinikon spoudon. Idryma Manoli Triantafyllidi. Ekdoseis Pataki.

13. Tzartzanos, A. 1963. Neoelliniki Syntaksis (Tis Koinis Dimotikis). Athenes: Organismos Ekdoseon Didaktikon Vivlion. 